\title{
The Global Subduction/Obduction Rates: Their Interannual and Decadal Variability
}

\author{
LING LING LIU \\ Key Laboratory of Ocean Circulation and Waves, Institute of Oceanology, Chinese Academy of Sciences, Qingdao, \\ and State Key Laboratory of Tropical Oceanography, South China Sea Institute of Oceanology, \\ Chinese Academy of Sciences, Guangzhou, China \\ RUI XIN HUANG \\ Department of Physical Oceanography, Woods Hole Oceanographic Institution, Woods Hole, Massachusetts
}

(Manuscript received 30 November 2010, in final form 4 July 2011)

\begin{abstract}
Ventilation, including subduction and obduction, for the global oceans was examined using Simple Ocean Data Assimilation (SODA) outputs. The global subduction rate averaged over the period from 1959 to 2006 is estimated at $505.8 \mathrm{~Sv}\left(1 \mathrm{~Sv} \equiv 10^{6} \mathrm{~m}^{3} \mathrm{~s}^{-1}\right)$, while the corresponding global obduction rate is estimated at $482.1 \mathrm{~Sv}$. The annual subduction/obduction rates vary greatly on the interannual and decadal time scales. The global subduction rate is estimated to have increased $7.6 \%$ over the past 50 years, while the obduction rate is estimated to have increased $9.8 \%$. Such trends may be insignificant because errors associated with the data generated by ocean data assimilation could be as large as $10 \%$. However, a major physical mechanism that induced these trends is primarily linked to changes in the Southern Ocean. While the Southern Ocean plays a key role in global subduction and obduction rates and their variability, both the Southern Ocean and equatorial regions are critically important sites of water mass formation/erosion.
\end{abstract}

\section{Introduction}

Ventilation-related water mass formation and erosion is a key component of global oceanic circulation, and they are closely linked to the climate and cycling of many elements through the atmosphere-ocean interface. For the wind-driven gyre in the upper ocean, the early theory is based on the ideal fluid assumption for the permanent pycnocline below the annual maximal mixed layer base, for example, Luyten et al. (1983) and Huang (1988b,a); however, the role of the seasonal cycle is not included there. In the subsequently developed theory of water mass formation, the role of the seasonal cycle is included and water mass exchange across the base of the mixed layer is emphasized. The commonly used terms to quantify these processes for the open ocean are subduction and obduction, defined as the large-scale transfer of fluid leaving (entering) the surface mixed layer irreversibly into (from) the permanent pycnocline.

Corresponding author address: Ling Ling Liu, Key Laboratory of Ocean Circulation and Waves, Institute of Oceanology, Chinese Academy of Sciences, Qingdao 266071, China.

E-mail: liull@qdio.ac.cn
Subduction/obduction has been widely used as tools describing kinematical and dynamical processes coupling the mixed layer and the ocean interior. Sites of water mass formation through subduction are crucial windows for the communication of atmospheric signals and tracer input to the oceans. Likewise, water mass erosion through obduction, the opposite phase, is crucially important for transferring tracers and climate signals from the interior ocean to the air-sea boundary (Fig. 1). In particular, water mass formation/erosion may have a close link with many important marine chemical and ecologic cycles, especially with the carbon cycle, which plays a vital role in the climate and ecology of our planet. It is well known that carbon dioxide can be brought into the deep ocean through water mass formation at high latitudes. The returning half of the carbon cycle is the release of carbon from the ocean to the atmosphere through upwelling of water mass from the deep ocean and eventually through obduction, which is defined as the annual net volume flux from the permanent pycnocline to the mixed layer in the upper ocean. For example, the exchange between the upper ocean and deep ocean at latitudes plays a critical role in determining the atmospheric $p \mathrm{CO}_{2}$ (Sarmiento and Toggweiler 1984). This exchange is closely related to water mass formation/erosion 


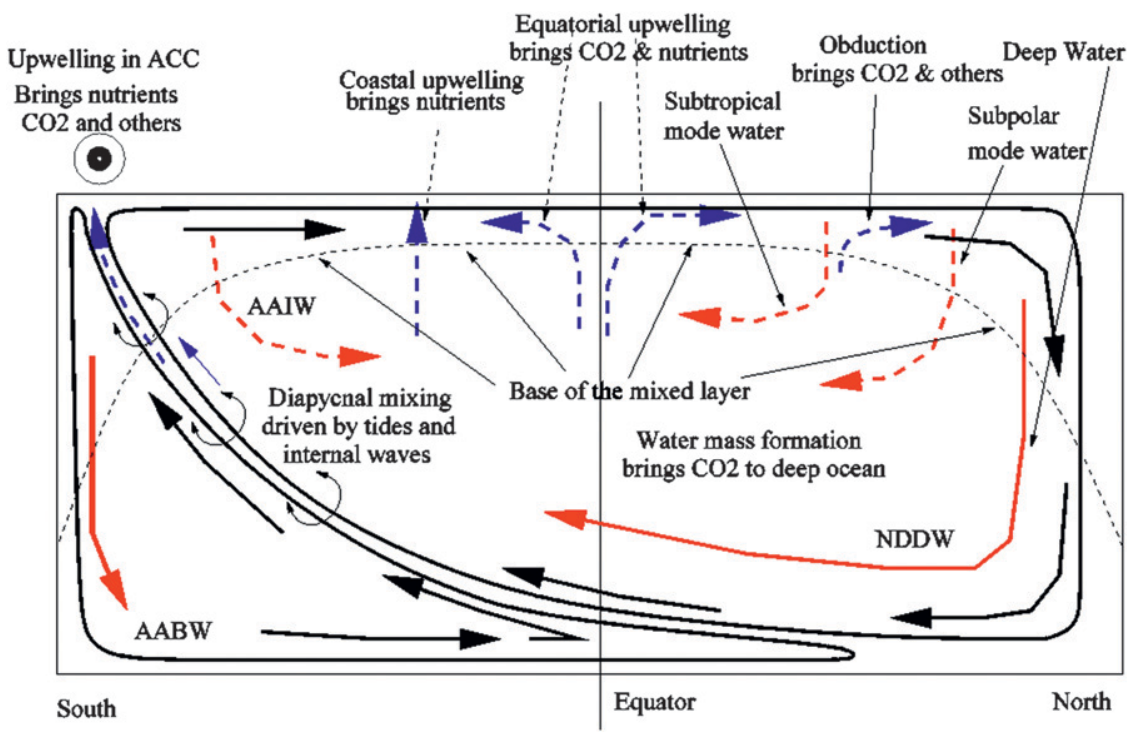

FIG. 1. Sketch indicating the role of subduction/obduction associated with the oceanic circulation, climate, and carbon cycle. Black lines with an arrow indicate flows associated with meridional overturning cells, red lines with an arrow depict water mass formation associated with subduction, and blue lines with an arrow indicate water mass erosion associated with obduction.

and can be examined in terms of the subduction/obduction rate for the global ocean. Therefore, understanding the subduction/obduction process, and quantifying the largescale subduction/obduction rate, is extremely important for the oceanic general circulation, climate, ecosystem, and studies of carbon cycle, et cetera.

Water mass formation/erosion and the subsequent modification have been widely studied over the past decades. In particular, the subject of mode water, including its generation, transport, transformation and variability, has been widely studied by many investigators. Hanawa and Talley (2001) provided a thorough review for this subject and a comprehensive list of the most important and relevant references. Since water mass formation and erosion are complicated phenomena, there are different viewpoints about them.

First, many investigators use the concept of ventilation rate. The advantage of using this concept is that it can be calculated by numerical models through diagnosis of the concentration in the surface layer of a specifically designed tracer. Brandt et al. (2007) provided the most updated example along this line of approach. In addition, ventilation rate has been widely used in marine chemistry; thus, this approach can be conveniently compared to the results based on chemical tracer analysis. A disadvantage is that the contribution from subduction and obduction is not clearly separated in this approach.

Second, water mass formation and erosion take place in the surface mixed layer and subsurface ocean. In addition, these processes work continuously in space and time; that is, water mass properties are continuously modified along the trajectory of each water parcel. As a result, any definition of water mass formation/erosion rate can only capture these complicated processes in a specific time and space domain.

Furthermore, there are two commonly used approaches to estimate the rate of water mass formation/erosion. The first can be classified as the thermodynamic method, postulated by Walin (1982). This approach makes a direct connection between surface buoyancy forcing and water mass formation in the upper ocean; thus, it can provide useful information regarding the role of climate change and water mass formation/erosion. This approach has been widely used by many investigators in analyzing hydrographic data to diagnose the corresponding water mass formation/erosion rate, for example, Speer and Tziperman (1992), Speer et al. (1995), Marshall et al. (1999), Nurser et al. (1999), Brambilla and Talley (2008), and Brambilla et al. (2008).

In general, within the thermodynamic framework the water mass formation rate in the upper ocean is the focus, and the base of the mixed layer is not treated as a special interface. The disadvantage is that a water mass formed in the upper ocean, inferred through this approach, does not necessarily enter the interior ocean below the mixed layer. For example, Brambilla and Talley (2008) pointed out that the core of minimum potential vorticity of Subpolar Mode Water is above the annual maximal mixed layer base. As 
discussed by Garrett et al. (1995), Garrett and Tandon (1997), and Marshall et al. (1999), air-sea fluxes are not the only forcing involved in the water mass formation/erosion. In fact, strong mixing across the base of the mixed layer and lateral mixing within the mixed layer also play critically important roles in reshaping water mass properties. The role of lateral mixing is particularly important for Subpolar Mode Water formation, for example, Brambilla and Talley (2008). In addition, strong diapycnal/lateral mixing below the mixed layer continuously modifies the water mass properties, for example, Speer (1997), and Lumpkin and Speer (2003).

The second approach can be classified as the dynamical or kinematic method, which uses dynamical information of mixed layer properties, including the density and depth of the mixed layer base, plus the velocity field generated from a numerical model or inferred from climatological data, for example, Woods and Barkmann (1986) and Marshall et al. (1993). This approach was refined by Qiu and Huang (1995), who postulated a more accurate account of subduction and obduction. Accordingly, the annual mean subduction and obduction rates are defined as the net volume flux from the mixed layer to the permanent pycnocline (subduction) and that from the permanent pycnocline to the mixed layer (obduction).

This approach is focused on the mass communication between the mixed layer and subsurface ocean below; thus, an idealized concept of the mixed layer base is used in this method, and an accurate account of the mixed layer base is a technically critical aspect of the calculation. Accordingly, this approach does not provide information regarding the amount of water mass formation within the upper ocean and the continuous modification of water mass after subduction or before obduction. As a result, the water mass formation rate inferred from this method may be noticeably different from the other approach discussed above. However, this approach can provide a tracer flux across the mixed layer base, which is very useful for the study of climate and the global carbon cycle. Thus, we adopt this approach in this study and hope our calculation of the global subduction/obduction rate can shed light on water mass formation/erosion as seen from the base of the mixed layer.

It is worthwhile to emphasize that the concept of subduction/obduction applies to water mass formation/ erosion in the open ocean only. Water mass formation/ erosion can also take place in relatively narrow regions near the coasts. For example, strong along-shore wind can drive upwelling/downwelling in coastal areas. In addition, deep-water and bottom-water formation takes place in a narrow band along coasts or in semiclosed marginal seas, such as Antarctic Bottom Water formation (Orsi et al.1999), North Atlantic Deep Water formation (LeBel et al. 2008), and Mediterranean Outflow Water (Bryden and Stommel 1982). Therefore, the water mass formation/ erosion rate through subduction/obduction discussed in this study excludes the potential contribution associated with processes taking place in the relatively narrow coastal regions and semienclosed marginal seas.

In addition, water mass formation and erosion can also take place below the mixed layer through mixing processes. For example, based on detailed analysis of hydrographic data available, Brambilla and Talley (2008) and Brambilla et al. (2008) argued that Subpolar Mode Water in the North Atlantic Ocean is formed primarily through mixing below the mixed layer, not through the subduction processes discussed here. Therefore, we emphasize that the subduction/obduction calculated in this study is a rough first cut of the water mass formation/ erosion rate estimated through the interface between the annual maximal mixed layer base and the permanent pycnocline layers below.

Theoretical studies of subduction date back to Iselin (1939), who first suggested that water is pushed down through the surface layer by Ekman pumping. However, Stommel (1979) was the first to suggest that the annual subduction rate is virtually independent of the detailed seasonal mixed layer cycle and can be diagnosed from the late-winter mixed layer properties alone. The mechanism by which subduction occurs has been followed by a number of ideal-fluid pycnocline models that diagnose the subduction rate (e.g., Woods 1985; Huang 1990; Williams 1991; Qiu and Huang 1995; Williams et al. 1995; Marshall 1997).

Some attempts have been made to quantify the water mass formation through subduction. Qiu and Huang (1995) estimated the annual subduction rate using the Levitus and Hellerman and Rosenstein (1983) climatological data. According to their calculation, the total volume flux subducted from the mixed layer into the permanent pycnocline is $35.2 \mathrm{~Sv}\left(1 \mathrm{~Sv} \equiv 10^{6} \mathrm{~m}^{3} \mathrm{~s}^{-1}\right)$ over the entire North Pacific and $30.1 \mathrm{~Sv}$ in the North Atlantic. However, Qu et al. (2002) estimated the subduction rate in the North Pacific $\left(10^{\circ}-50^{\circ} \mathrm{N}\right)$ at $61.6 \mathrm{~Sv}$ using 5-day output from a high-resolution general circulation model, which took the effect of eddies into account. Trossman et al. (2009) estimated subduction rates of $17.4 \mathrm{~Sv}-19.0 \mathrm{~Sv}$ for several years, with nearly $50 \%$ error over the North Atlantic in $10^{\circ}-30^{\circ} \mathrm{N}$ from Argo; Archiving, Validation, and Interpretation of Satellite Oceanographic data (AVISO) satellite altimetry; Quick Scatterometer (QuikSCAT) scatterometry; and World Ocean Circulation Experiment (WOCE)/Atlantic Climate and Circulation Experiment (ACCE) data. Huang and Qiu (1998) analyzed the climatology and estimated the subduction rate at 21.6 Sv in the South Pacific. Karstensen and Quadfasel (2002) quantified the ventilation of the permanent 
thermocline of the Southern Hemisphere using climatological and synoptic observational data. According to their estimate, the subduction of water into the South Atlantic, South Indian, and South Pacific is $21 \mathrm{~Sv}, 35 \mathrm{~Sv}$, and 44 Sv, respectively. Furthermore, Qu et al. (2008) estimated the subduction rate in the South Pacific at 48.8 Sv from Argo and the World Ocean Database 2005 (WOD05; Boyer et al. 2006).

For the balance of water masses in the world's oceans, there must be a process going on in the opposite direction; that is, a water mass must be continuously converted into other types of water mass through some physical processes. However, in contrast to the general interest in understanding water mass formation through subduction, there has only been a very few studies related to water mass erosion through obduction. Qiu and Huang (1995) estimated the obduction rate at $7.8 \mathrm{~Sv}$ in the North Pacific and $23.5 \mathrm{~Sv}$ in the North Atlantic from the climatology. Trossman et al. (2009) estimated obduction rates of 13.9$20.5 \mathrm{~Sv}$ for several years, with nearly $50 \%$ error over the North Atlantic in $10^{\circ}-30^{\circ} \mathrm{N}$ from Argo, AVISO satellite altimetry, QuikSCAT scatterometry, and WOCE/ACCE data. It is clear that to have a complete picture of water mass balance in the World Ocean, we must calculate both subduction and obduction rates.

Recently, decadal variability of water mass formation has been investigated in many studies. For example, the variability of mode-water formation in the Southern Hemisphere was investigated using synoptic observational data (Bindoff and Church 1992; Bindoff and McDougall 2000; Johnson and Orsi 1997; Wong et al. 1999) as well as climate models (Banks et al. 2000). These studies show that the overall production of mode waters has increased over the past 10-20 years. Qu and Chen (2009)'s result revealed the existence of a North Pacific decadal variability in subduction rate from an eddy-resolving general circulation model, and much of the variability is due to changes in winter mixed layer depth.

In summary, although a lot of studies have been performed on subduction/obduction rates and their variability, there are still some crucial problems that remain unanswered.

1) Hanawa and Talley (2001) reviewed water mass formation in the World Ocean; however, the corresponding global map of water mass erosion is not yet available. So far, none of the studies about subduction/obduction covered the global oceans; for example, water mass formation/erosion through subduction/obduction in the equatorial band remains unclear. In particular, obduction has attracted less attention; thus, we do not have a unified picture of the global water mass formation/erosion, which is important for the studies of general oceanic circulation, climate, and biochemistry, among others.

2) Qu and Chen (2009) reported the interannual and decadal variability in the subduction rate in the North Pacific. Then, does the variability exist in the global subduction/obduction rate? If so, where is the critical region controlling the variability? These studies would provide useful information for the assessment of climatic change.

To resolve these problems, in this study we estimate the global subduction/obduction rates from 1959 to 2006 using the Simple Ocean Data Assimilation (SODA) outputs. Our calculation is based on the formula defined in Lagrangian coordinates, as discussed in section 2 . The global subduction rate and its variability are discussed in section 3 , and the obduction rate and its variability in section 4. Finally, we conclude in section 5.

\section{Data and method}

\section{a. The dataset}

SODA combines the Parallel Ocean Program (POP) model and a sequential estimation data assimilation method (Carton et al. 2000; Carton and Giese 2008). There are several versions of SODA, depending on the experiment setup. For the remainder of the paper, we use SODA to mean the SODA 2.0.2/2.0.4 product. SODA version 2.0.2 is forced by 40-yr European Centre for MediumRange Weather Forecasts Re-Analysis (ERA-40) wind stresses from 1958 to 2001 and assimilated all available data from hydrographic stations, XBTs, and floats but it does not use satellite altimetry. SODA version 2.0.4, identical to SODA 2.0.2 except it uses a merged product of QuikSCAT and the National Centers for Environmental Prediction-National Center for Atmospheric Research (NCEP-NCAR) reanalysis, extends SODA 2.0.2 from 2002 to 2007. SODA was created to reconstruct historical ocean climate variability on space and time scales similar to those captured by the atmospheric analysis project; thus, it may be favorable for our analysis of the climatic variability of ventilation.

The monthly mean temperature, salinity, and velocity fields of SODA are used in our calculation, which are mapped onto a $0.5^{\circ} \times 0.5^{\circ}$ horizontal grid with 40 levels. The mixed layer depth is defined as the depth at which $\sigma_{\theta}$ (potential density) differs by $0.125 \mathrm{~kg} \mathrm{~m}^{-3}$ from its value at the sea surface. The horizontal velocities taken from SODA are directly used in this study.

In previous studies, vertical velocity is calculated from Ekman pumping velocity, plus a reduction term due to the meridional velocity in the surface layer. This approach does not work for the equatorial band, where the Coriolis 
parameter is very small or vanishes. To overcome this problem, we have to use the vertical velocity diagnosed from the divergence/convergence of the SODA horizontal velocity; thus, it is quite noisy, especially near the boundary. To deal with problems associated with such a noisy vertical velocity field, we first smooth the vertical velocity diagnosed from SODA outputs (weighting 1-2-1 in both zonal and meridional directions), and then set an upper limit for the vertical velocity. According to Qiu and Huang (1995), the contribution of vertical pumping is not larger than $100 \mathrm{~m} \mathrm{yr}^{-1}$ in the subtropical ocean. In addition, observational data has shown that the maximum of equatorial upwelling is $2 \times 10^{-5} \mathrm{~m} \mathrm{~s}^{-1}$ or so (Weisberg and Qiao 2000; Johnson et al. 2001; Halpern et al. 1989). Based on the above reasoning, the upper limit of the vertical velocity is set at $3.2 \times 10^{-6} \mathrm{~m} \mathrm{~s}^{-1}\left(100 \mathrm{~m} \mathrm{yr}^{-1}\right)$ north (south) of $10^{\circ} \mathrm{N}(\mathrm{S})$, linearly increased to $2.0 \times$ $10^{-5} \mathrm{~m} \mathrm{~s}^{-1}$ at $5^{\circ} \mathrm{N}(\mathrm{S})$, and it is set as constant between $5^{\circ} \mathrm{N}$ and $5^{\circ} \mathrm{S}$, as shown in Fig. 2.

\section{b. The annual subduction/obduction rate}

The annual subduction rate can be calculated in Lagrangian coordinates using the following simplified formula (Woods 1985; Qiu and Huang 1995):

$$
S_{L}=-\bar{w}_{\mathrm{tr}}+\frac{1}{T}\left(h_{m, 0}-h_{m, 1}\right),
$$

where $T=1 \mathrm{yr}, \bar{w}_{\mathrm{tr}}$ is the vertical velocity averaged over the 1-yr Lagrangian trajectory, $h_{m, 0}$ and $h_{m, 1}$ denote the mixed layer depths along the trajectory at the beginning and ending of the first effective subducted trajectory, which is typically taken as March (September) in the Northern (Southern) Hemisphere. The first term in Eq. (1) represents the contribution from vertical pumping at the base of the mixed layer, and the second term the contribution from lateral induction due to the slope of the mixed layer base. It is noted that by definition, the subduction rate should be nonnegative; a negative value calculated from this method should be interpreted as a zero subduction rate (Qiu and Huang 1995).

Similarly, the annual obduction rate can also be calculated in Lagrangian coordinates using the simplified formula (Woods 1985; Qiu and Huang 1995):

$$
O_{L}=\bar{w}_{\mathrm{tr}}+\frac{1}{T}\left(h_{m, 0}-h_{m,-1}\right),
$$

where $h_{m, 0}\left(h_{m,-1}\right)$ is the mixed layer depth at the beginning (ending) of the backward trajectory, which is typically taken as March (September) in the Northern (Southern) Hemisphere. In the same way, a negative value calculated from this method should be interpreted as a zero obduction rate.

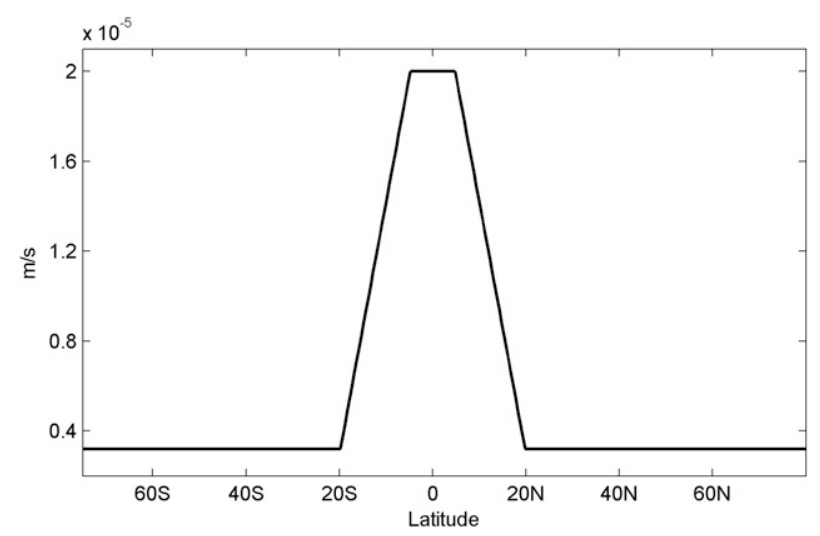

FIG. 2. Upper limit of vertical velocity $\left(\mathrm{m} \mathrm{s}^{-1}\right)$ imposed in the data analysis.

However, for the SODA monthly outputs, subduction/ obduction does not occur first in March (September) in the Northern (Southern) Hemisphere at all the stations, as shown in Fig. 3. That is, it was not suitable to calculate the subduction/obduction rate simply using the trajectory released/received in March (September) in the Northern (Southern) Hemisphere as adopted in most previous studies. Therefore, in this study, we use the trajectory released/received at the time with the maximal mixed layer depth in the corresponding year to estimate the annual subduction/obduction rate.

\section{The subduction rate and its variability}

We begin with calculating the global subduction rate from SODA outputs. For a given station, we first ascertain the month with the maximal mixed layer depth in the given year; then, water parcels are released and the corresponding 1-yr trajectory forward in space and time are traced with a regular interval of 2 days; finally, the subduction rate is calculated according to Eq. (1).

\section{a. The subduction rate}

The annual subduction rate for the global oceans averaged from 1959 to 2006 is shown in Fig. 4. It is well known that regions of high subduction rate are generally characterized by relatively thick wintertime mixed layers. In the World Ocean, the thickest mixed layers are in the northern North Atlantic and around the northern region of the Southern Ocean in the Pacific and eastern Indian sectors. These regions of thick winter mixed layers are associated with a large subduction rate in the North Atlantic and Antarctic Circumpolar Current (ACC) region, as can be seen from the meridional/zonal distribution of the zonally/ meridionally integrated results (left/bottom, Fig. 4). The total volumetric subduction rate integrated over the global oceans averaged from 1959 to 2006 is estimated at 

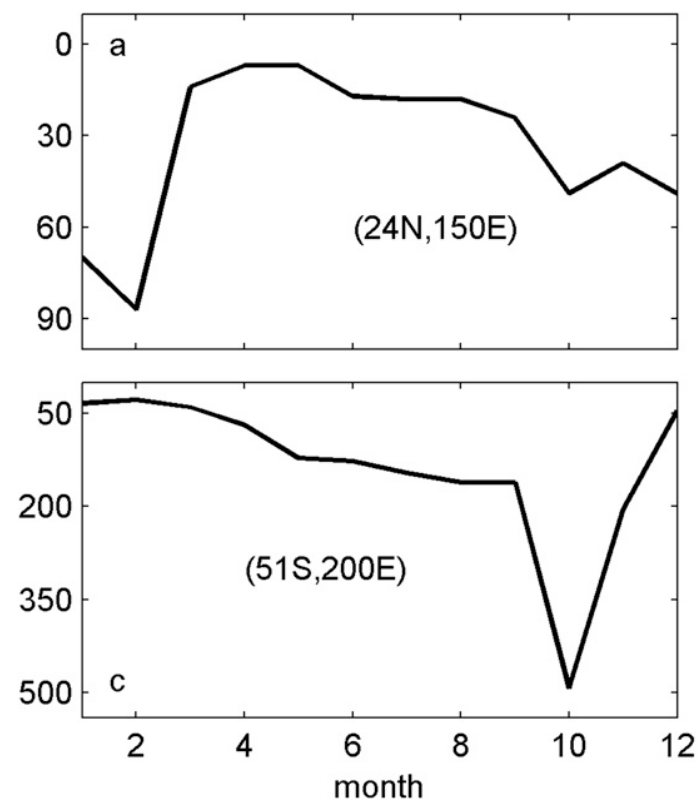
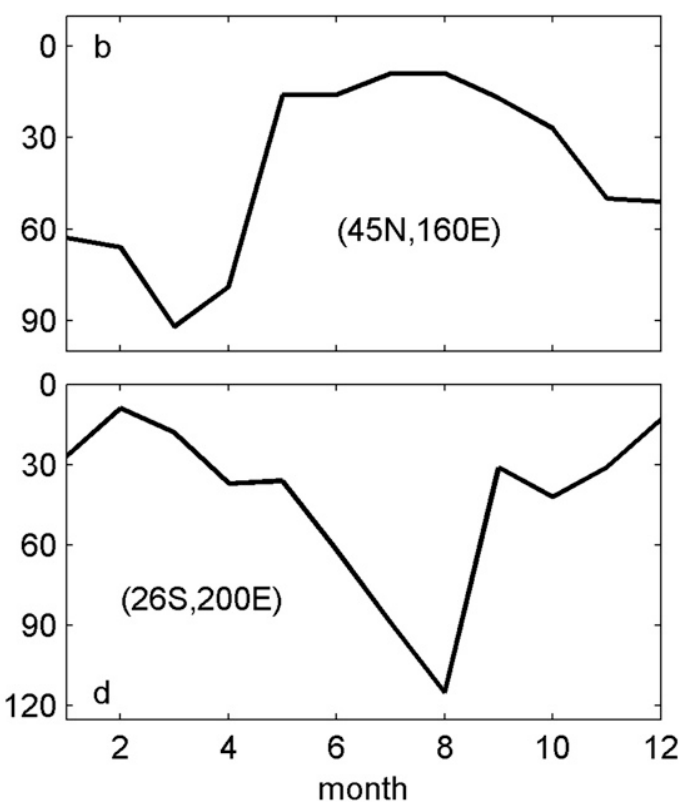

FIG. 3. Annual cycle of the mixed layer depth (m) at four different stations in year 2004: (a) $24^{\circ} \mathrm{N}, 150^{\circ} \mathrm{E}$; (b) $45^{\circ} \mathrm{N}$, $160^{\circ} \mathrm{E}$; (c) $51^{\circ} \mathrm{S}, 200^{\circ} \mathrm{E}$; and (d) $26^{\circ} \mathrm{S}, 200^{\circ} \mathrm{E}$.

505.8 Sv, with 157.4 Sv in the Atlantic, 225.7 Sv in the Pacific, and $122.7 \mathrm{~Sv}$ in the Indian Ocean. Moreover, the subduction rate integrated over the entire Southern Ocean $^{1}$ is $177.4 \mathrm{~Sv}$ (Table 1).

However, according to the previous studies (Qiu and Huang 1995; Karstensen and Quadfasel 2002), the subduction rate for the global oceans, excluding the equatorial band, is $\sim 160 \mathrm{~Sv}$ from the climatological datasets. It seems that our result is much larger. To validate the high subduction rate obtained from SODA outputs year by year, we carried out an additional analysis. Taking the North Pacific, for example, the annual subduction rate estimated from climatologically mean SODA outputs (multiyear mean mixed layer depth and velocity fields) is $38.0 \mathrm{~Sv}$, which is slightly larger than the result of 35.2 Sv by Qiu and Huang (1995); moreover, the spatial distribution (figure omitted) is quite similar. On the other hand, Qu and Chen (2009) estimated the subduction rate from $20^{\circ}$ to $50^{\circ} \mathrm{N}$ at $49.3 \mathrm{~Sv}$ from the OGCM for the Earth Simulator (OFES) data, while our result is $50.3 \mathrm{~Sv}$ in the same region. Therefore, it seems that the usage of climatologically mean fields may greatly underestimate the annual subduction rate, owing to nonlinearity associated with the lateral

\footnotetext{
${ }^{1}$ The Southern Ocean is the region between $37.5^{\circ}$ and $65^{\circ} \mathrm{S}$ in the South Pacific and between $35^{\circ}$ and $65^{\circ} \mathrm{S}$ in the other Southern Hemisphere oceans; the zonal boundaries between the Atlantic, Indian, and Pacific Oceans are $30^{\circ} \mathrm{E}, 145^{\circ} \mathrm{E}$, and $70^{\circ} \mathrm{W}$, respectively; same as the ACC referred to in this paper.
}

induction term (Trossman et al. 2009), which can also be proved through mathematical formula as below.

The annual subduction rate consists of two terms, the vertical pumping and the lateral induction. The vertical pumping term is the vertical velocity averaged over the 1 -yr trajectory; this is a weakly nonlinear term. The lateral induction is the product of lateral velocity and mixed layer depth gradient. In Lagrangian coordinates, it can be reduced to

$$
\Delta h / T=\alpha x / T,
$$

where $\alpha$ is the slope of the mixed layer depth and $x$ is the length of the trajectory over the period of $T=1 \mathrm{yr}$. Due to the climate variability, both $\alpha$ and $x$ may vary; that is, they can be written in the form of $\alpha_{0}+\alpha^{\prime}$ and $x_{0}+x^{\prime}$. Therefore, the lateral induction term is

$$
\Delta h / T=\left(\alpha_{0}+\alpha^{\prime}\right)\left(x_{0}+x^{\prime}\right) / T .
$$

The mean lateral induction is

$$
\begin{aligned}
\overline{\Delta h / T} & =\overline{\left(\alpha_{0}+\alpha^{\prime}\right)\left(x_{0}+x^{\prime}\right)} / T \\
& =\alpha_{0} x_{0} / T+\alpha_{0} \overline{x^{\prime}} / T+\overline{\alpha^{\prime}} x_{0} / T+\overline{\alpha^{\prime} x^{\prime}} / T .
\end{aligned}
$$

However, note that $\alpha_{0}$ and $x_{0}$ indicate values obtained from climatological fields, which are different from $\sum_{i=1}^{n} \alpha_{i} / n$ and $\sum_{i=1}^{n} x_{i} / n$, the mean of values for individual years; first, the shape and special location of the 1-yr trajectories determined from an individual year is quite 


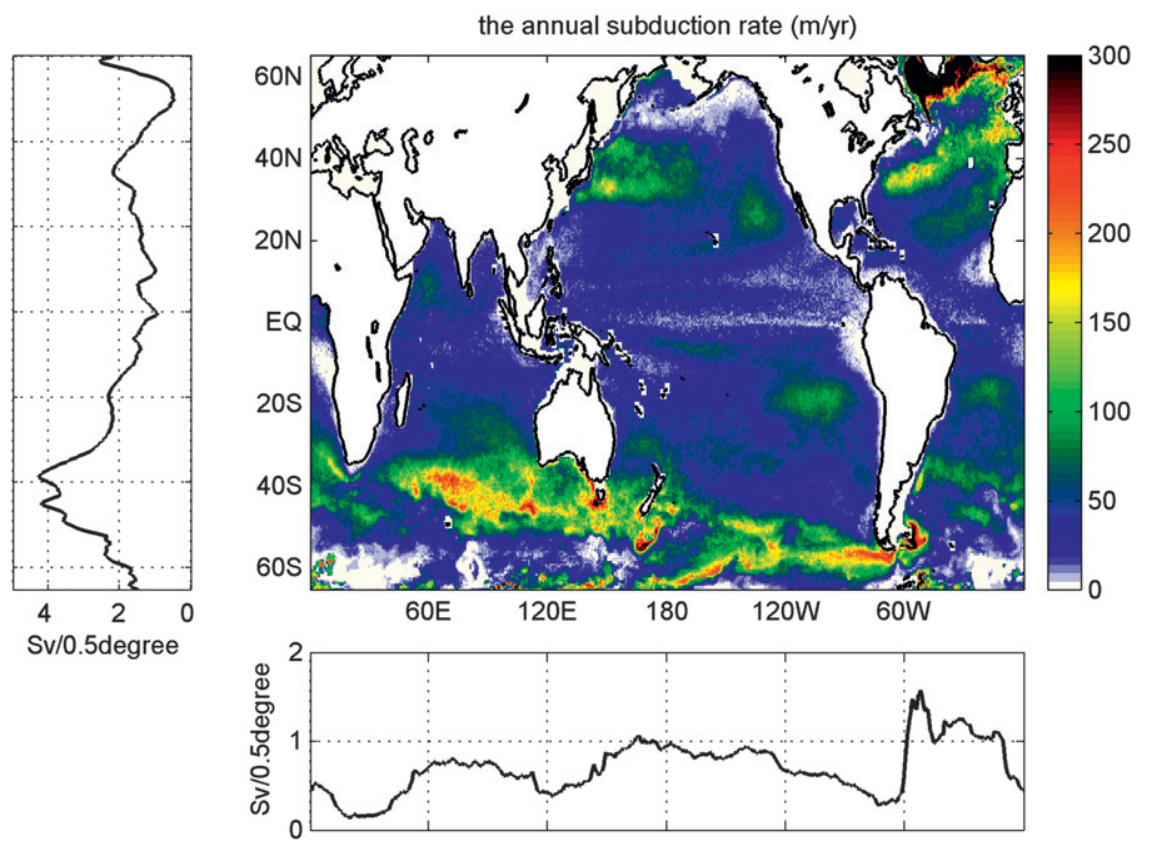

FIG. 4. Horizontal distribution of the annual subduction rate $\left(\mathrm{m} \mathrm{yr}^{-1}\right)$ averaged from 1959 to 2006: (left) meridional distribution of the zonally integrated subduction rate and (bottom) zonal distribution of the meridionally integrated subduction rate.

different from that obtained from the climatological mean fields; second, the distance $x$ is determined by the horizontal velocity averaged over the trajectory; thus, it is also a nonlinear term. As a result, the means of the perturbation, $\overline{\alpha^{\prime}}$ and $\overline{x^{\prime}}$, are nonzeros; that is, the second and third terms on the right-hand side in Eq. (5) are nonzero. Therefore, contributions from these terms are major sources of rectification associated with the lateral induction.

It is readily seen that due to the rectification of nonlinearity associated with the lateral induction term, the mean subduction rate obtained by averaging the corresponding rates calculated from individual years is much larger than the subduction rate calculated from the multiyear mean fields of velocity and mixed layer depth, as discussed by Trossman et al. (2009). The results calculated from the dataset year by year may better represent the ventilation of the thermocline, which is very important for the studies of the oceanic general circulation, climate, and biochemistry, among others.

The distribution of the subduction rate in density coordinates is shown in Fig. 5. This distribution figure is generated as follows. We first compute the subduction rate in density coordinates for each year from 1959 to 2006; afterward, the multiyear mean distribution in density coordinates is obtained by averaging over the corresponding period.

Mode water is a particular type of water mass characterized by its abundance and homogeneity in its properties, and its formation may play an important role in large-scale ocean dynamics, as well as the large-scale air-sea interaction. Thus, according to the spatial distribution of the annual subduction rate, we refigure the formation sites of mode water for the global oceans (Fig. 6), where the number indicates the average potential density for the corresponding mode water, which is defined as $\sum_{i} S_{i} \sigma_{i} / \sum_{i} S_{i}$, where $S_{i}$ and $\sigma_{i}$ are the subduction rate and corresponding potential density at each grid, and the integration is within the formation area of each mode water as marked in Fig. 6, which is determined based on the local subduction rate being larger than $80 \mathrm{~m} \mathrm{yr}^{-1}$ for the Subtropical Mode water and $100 \mathrm{~m} \mathrm{yr}^{-1}$ for the North Atlantic Subpolar Mode Water and Subantarctic Mode Water. This map is quite similar to that of Hanawa and Talley (2001), which was based on observations available at that time. The somewhat minor difference

TABLE 1. Subduction rate (Sv) averaged from 1959 to 2006. Note that although the Southern Ocean is listed in the third row, its contributions are included as part of the Southern Hemisphere.

\begin{tabular}{lcrrr}
\hline & Atlantic & Pacific & Indian & Sum \\
\hline Northern Hemisphere & 90.2 & 82.4 & 10.9 & 183.5 \\
Southern Hemisphere & 67.2 & 143.3 & 111.8 & 322.3 \\
Southern Ocean & 37.0 & 70.0 & 70.4 & 177.4 \\
Sum & & & & \\
\hline
\end{tabular}




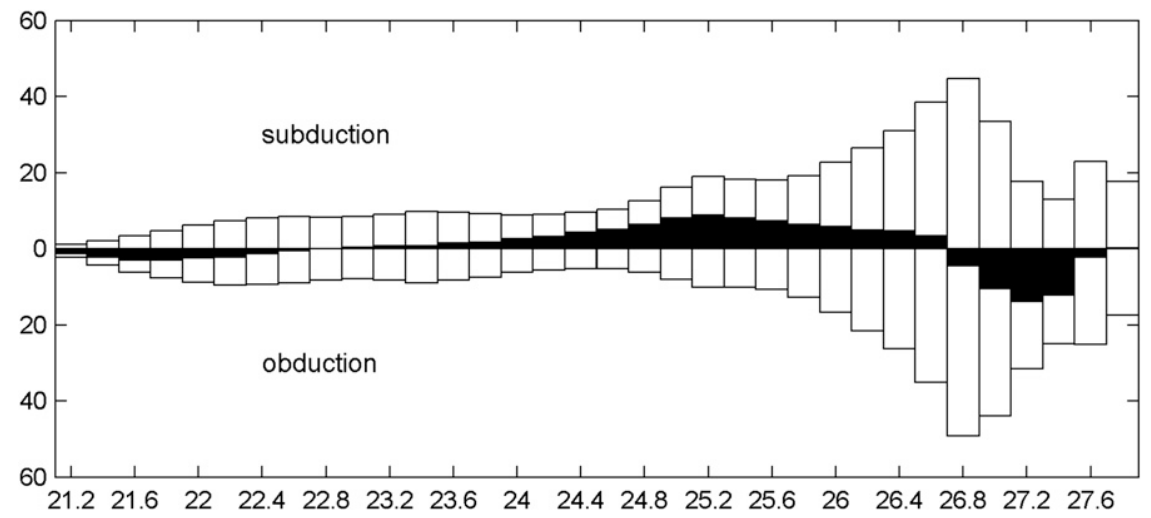

FIG. 5. Subduction/obduction rates per $0.2 \sigma_{\theta}$ interval as a function of density for the global oceans: black shades indicate the difference between subduction and obduction (subduction obduction).

in the pattern and the average potential density assigned to each mode water is due to the usage of different data to generate these two maps.

\section{1) NORTH PACIFIC OCEAN}

The distribution of subduction rate per $0.2 \sigma_{\theta}$ as a function of potential density in each basin is shown in Fig. 7. In the North Pacific, the subduction rate peak around 25.0 $25.2 \sigma_{\theta}$ (top-left panel, Fig. 7) is associated with the formation of the North Pacific Subtropical Mode Water (Masuzawa 1969; Suga et al. 1989), which can be found throughout the northwestern part of the subtropical gyre (Fig. 6). A dense type of Subtropical Mode Water, North Pacific Central Mode Water (Nakamura 1996; Suga et al. 1997), is associated with the subpolar front. These two types of mode water are marked by two patches with mean density $\sigma_{\theta}=25.4$ and $\sigma_{\theta}=26.5 \mathrm{~kg} \mathrm{~m}^{-3}$ in the western North Pacific in Fig. 6. The third, low density, mode water of the subtropical gyre is found in the eastern North Pacific (Hautala and Roemmich 1998); through our analysis of SODA output, this low-density mode water has a mean density of $\sigma_{\theta}=24.7 \mathrm{~kg} \mathrm{~m}^{-3}$, as shown in the eastern part of North Pacific in Fig. 6.

\section{2) North Atlantic Ocean}

The North Atlantic Subtropical Mode Water (Eighteen Degree Water, Worthington 1959) is mainly formed just south of the Gulf Stream extension (shown as a patch with mean density $\sigma_{\theta}=26.3 \mathrm{~kg} \mathrm{~m}^{-3}$, Fig. 6); a relatively high-density subtropical mode water of the

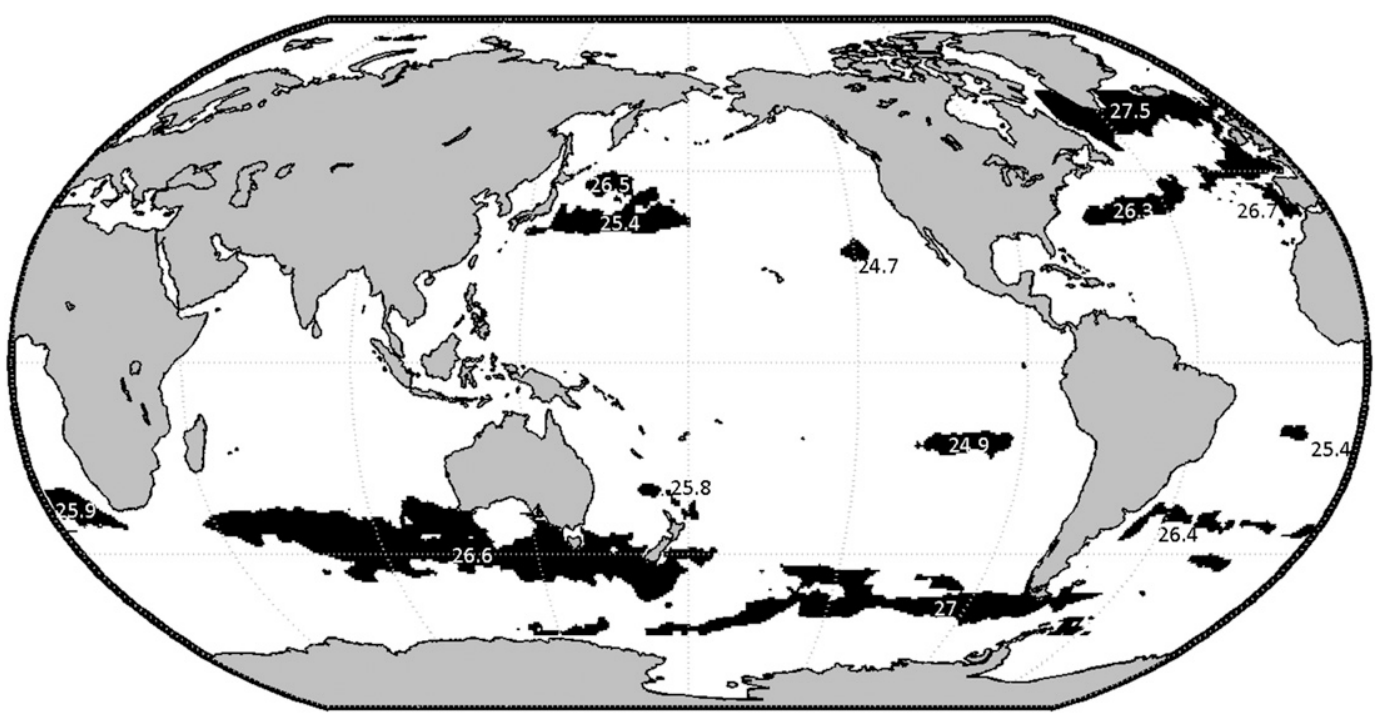

FIG. 6. Sites of mode water formation through subduction in the World Ocean, with numbers indicating the average potential density of the corresponding mode water. 

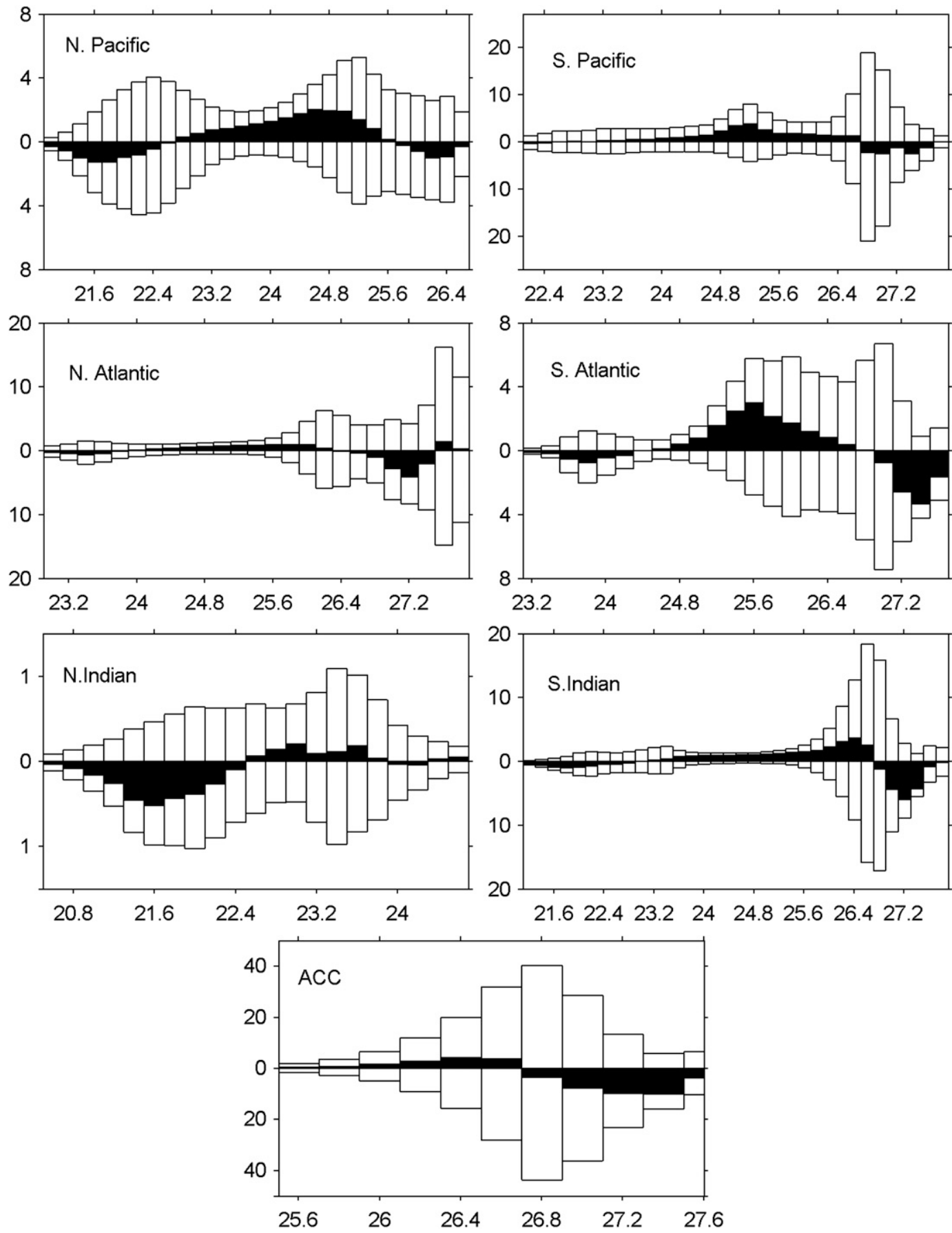

FIG. 7. Subduction/obduction rates $\left(\mathrm{Sv} / 0.2 \sigma_{\theta}\right)$ as a function of density for the North Pacific, South Pacific, North Atlantic, South Atlantic, northern Indian, and southern Indian Oceans, as well as the ACC region. Black shades indicate the difference of subduction and obduction (subduction - obduction), and North Pacific (Atlantic, Indian) indicates the region north of the equator, and South Pacific (Atlantic, Indian) south of the equator.

eastern subtropical gyres, the Madeira Mode Water (shown as a patch with mean density $\sigma_{\theta}=26.7 \mathrm{~kg} \mathrm{~m}^{-3}$ ) (Siedler et al. 1987), is analogous to the North Pacific Eastern Subtropical Mode Water. Moreover, the single subduction peak in the North Atlantic (Fig. 7) corresponds to the formation of Subpolar Mode Water (McCartney and Talley 1982) with a higher density of mean $\sigma_{\theta}=27.5$ $\mathrm{kg} \mathrm{m} \mathrm{m}^{-3}$, shown as a patch in Fig. 6 . 

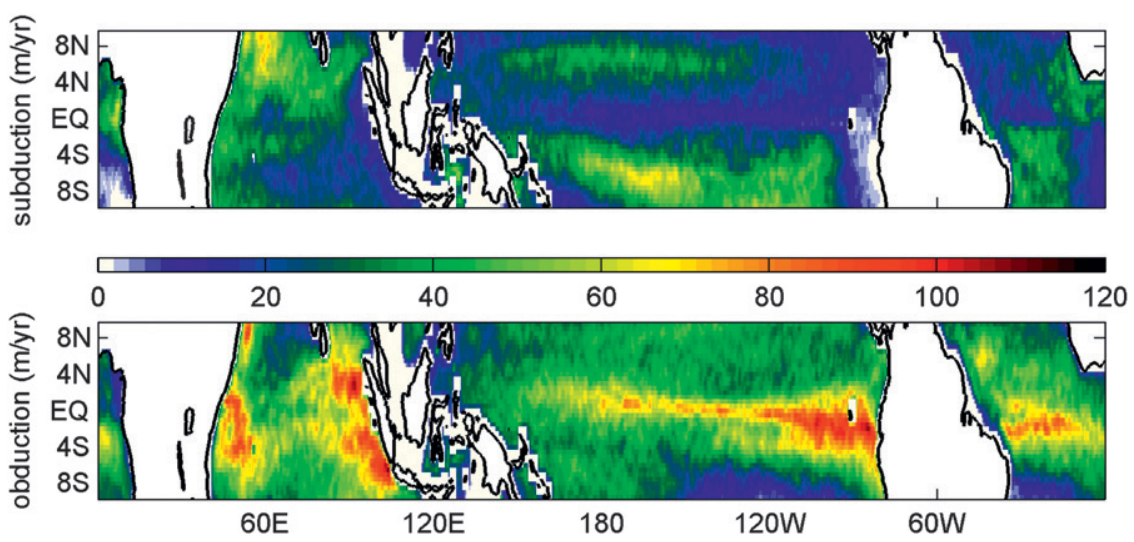

FIG. 8. Annual (top) subduction and (bottom) obduction rates $\left(\mathrm{m} \mathrm{yr}^{-1}\right)$ in the equatorial band $\left(10^{\circ} \mathrm{N} / \mathrm{S}\right.$ of the equator $)$ averaged from 1959 to 2006.

\section{3) SOUTHERN OCEAN}

The Southern Ocean is dominated by major fronts of the Antarctic Circumpolar Current (ACC), corresponding to the formation of the Subantarctic Mode Water primarily in the southeast Pacific and southeast Indian Ocean (McCartney 1982) within the density range of 26.4-27.2 $\sigma_{\theta}$ (bottom panel, Fig. 7). Also, as seen in the right panel of Fig. 7, in each basin there is a subduction peak in the given density range associated with the Subantarctic Mode Water.

\section{4) Subtropical South Atlantic Ocean}

The South Atlantic subtropical gyre has several prominent fronts, each with its own Subtropical Mode Water (Tsuchiya et al. 1994; Provost et al. 1999; shown in Fig. 6), which can be classified as South Atlantic Subtropical Mode Water (Provost et al. 1999), shown as a patch with mean density $\sigma_{\theta}=26.4$ $\mathrm{kg} \mathrm{m}^{-3}$, and the South Atlantic Eastern Subtropical Mode Water (Provost et al. 1999), shown as a patch with mean density $\sigma_{\theta}=25.9 \mathrm{~kg} \mathrm{~m}^{-3}$. Moreover, there is another subtropical mode water (Tsuchiya et al. 1994), formed mainly in the region between $15^{\circ}$ and $20^{\circ} \mathrm{S}$ (shown as a patch with mean density $\sigma_{\theta}=25.4$ $\mathrm{kg} \mathrm{m}^{-3}$ in Fig. 6), which is associated with Subtropical Underwater.

\section{5) Subtropical South Pacific Ocean}

In the South Pacific, there is a relatively small amount of Subtropical Mode Water formation (shown as a patch with mean density $\sigma_{\theta}=25.8 \mathrm{~kg} \mathrm{~m}^{-3}$ in Fig. 6) (Roemmich and Cornuelle 1992); meanwhile, a shallow and lowdensity Subtropical Mode Water (shown as a patch with mean density $\sigma_{\theta}=24.9 \mathrm{~kg} \mathrm{~m}^{-3}$ ) (Tsuchiya and Talley 1996) is found in the southeastern Pacific.

\section{6) Subtropical South Indian Ocean}

Unfortunately, our results (Fig. 6) cannot reveal clearly the formation sites of Indian Ocean Subtropical Mode Water (Toole and Warren 1993). This problem may indicate some inaccuracy of the SODA simulation in the Indian Ocean sector; however, the detail of this problem is left for further study.

\section{7) Equatorial OCEAN}

The equatorial band constitutes the major part of the World Ocean; thus, water mass formation and erosion in the equatorial band is potentially an important component of the water mass cycle in the World Ocean. However, owing to a simple technical reason, as previously mentioned, this area has not been covered in most previous studies on water mass formation. According to our calculation based on the model vertical velocity fields, the total volume flux subducted from the mixed layer to the permanent pycnocline in the equatorial ocean $\left(10^{\circ} \mathrm{S}, 10^{\circ} \mathrm{N}\right)$ is $52.9 \mathrm{~Sv}$, and the spatial distribution is shown in the top panel of Fig. 8. It is clear that subduction within the equatorial band constitutes a nonnegligible portion of the water mass formation in the World Ocean. It can be readily seen (Fig. 8) that the subduction in the equatorial ocean is mainly distributed outside $5^{\circ} \mathrm{N} / \mathrm{S}$ in the Pacific, Atlantic, and north Indian Oceans.

\section{b. The subduction rate variability}

It is well known that water mass formation is not a steady process in the ocean. Because of climate variability, water mass formation rate varies on interannual and decadal time scales. The time series of the annual mean global water mass formation rate between 1959 and 2006 diagnosed from SODA outputs is given in the top-left panel of Fig. 9. It seems that, although the amplitude of the interannual variability of the global subduction rate before 

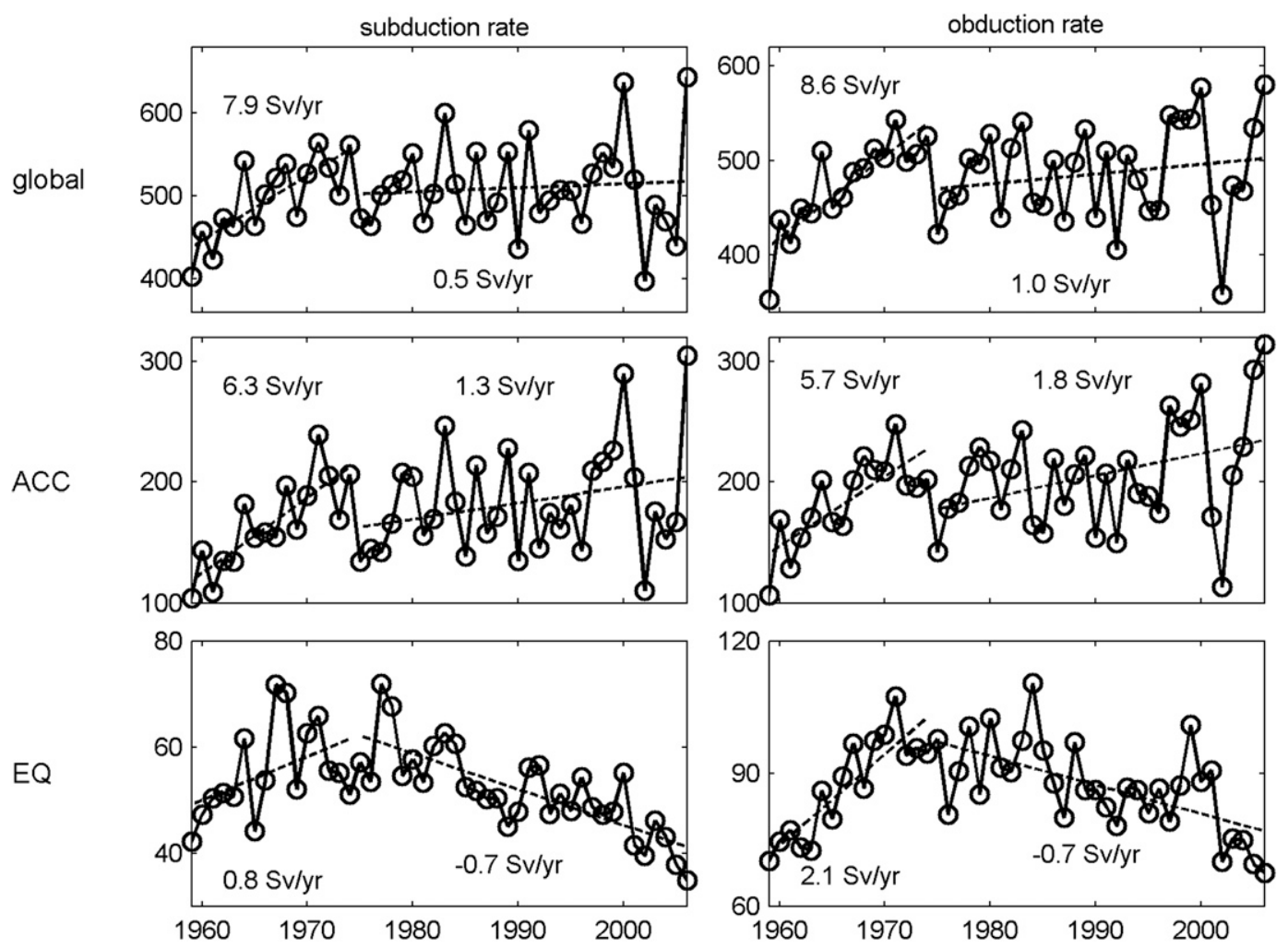

FIG. 9. Time series of the total (left) subduction and (right) obduction rate from 1959 to 2006 for the (top) global oceans, (middle) the ACC region, and (bottom) the equatorial band (Sv). Numbers inside each panel indicate the growth rate of the total annual subduction rate for the corresponding period.

1975 is small, it shows an obvious trend, as illustrated by the dotted line, with a growth rate of $7.9 \mathrm{~Sv} \mathrm{yr}^{-1}(27 \%$ increase) from 1959 to 1974. However, after 1975 the amplitude of interannual variability is largely increased, while the increasing trend decreases. On the whole, the global subduction rate increased $7.6 \%$, with a growth rate of $0.8 \mathrm{~Sv} \mathrm{yr}{ }^{-1}$, over the past 50 years. Many aspects of water mass formation and erosion discussed in this study are directly linked to the regime shift or the reorganization of the global atmospheric circulation. Many studies have been devoted to the regime shift, for example, Mantua et al. (1997) and Nakamura et al. (1997). The exactly dynamical relation between the regime shift and the water mass formation and erosion in the World Ocean is an extremely important issue deserving of further study; however, it is beyond the scope of this study.

The annual variability of the globally integrated subduction rate and its components are shown in the topleft panel of Fig. 10. It is readily seen that variability of the subduction rate (blue circles) is primarily controlled by the lateral induction (red stars), and the variability of the vertical pumping (green diamonds) is extremely small. Furthermore, to identify exactly the dynamics related to variability in the subduction rate, we carried out additional calculations of subduction, in which the year-to-year variable mixed layer depth and climatologically mean monthly velocity are used. The annual subduction rate from the new calculations is similar to that from standard calculations (figure omitted). Furthermore, as shown in the top-right panel of Fig. 10, the difference between the subduction rate anomaly from the new calculations and that from the standard calculations (magenta squares) is primarily due to the difference between the vertical pumping anomaly from the new calculations and that from the standard calculations (cyan pentagrams). In addition, the difference between the lateral induction anomaly from these calculations (black crosses) is minor. Therefore, we come to the conclusion that interannual variability of the globally integrated subduction rate is primarily due to changes in the lateral induction, which in turn is associated mainly with the variability in the mixed layer depth.

As is well known, the ocean's mixed layer can be greatly influenced by either surface wind stirring or surface convection; the wind stress dataset from NCEPNCAR (left panels in Fig. 11) indicates that over the past 50 years, changes in wind stress are characterized by a noticeable intensification of the westerlies over the 

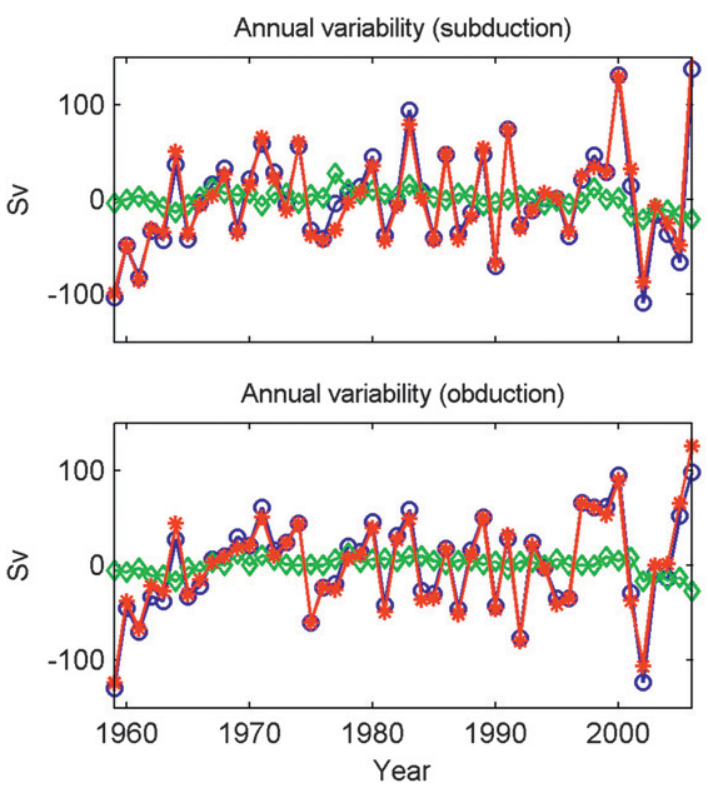

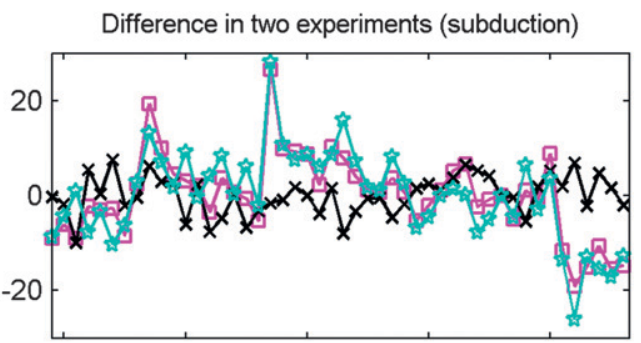

Difference in two experiments (obduction)

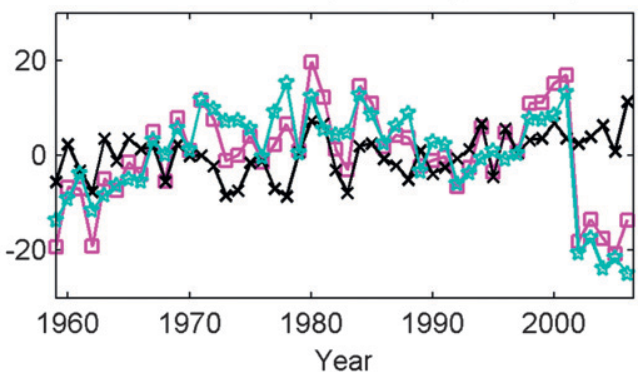

FIG. 10. (left) Annual variability of (top) subduction and (bottom) obduction rates: total subduction/obduction (blue circles), vertical pumping term (green diamonds), and lateral induction term (red stars). (right) Difference between the annual variability of (top) subduction and (bottom) obduction rates obtained from new calculations (based on year-to-year variable mixed layer depth and climatologically monthly-mean velocity) and those from the standard calculations: total subduction/obduction (magenta squares), the vertical pumping term (cyan pentagrams), and the lateral induction term (black crosses). All rates are the globally integrated terms (Sv).

ACC region and a weakening of the easterlies over the equatorial region; moreover, the heat flux dataset from the NCEP reanalysis (right panels in Fig. 11) shows great variability, especially the enhanced heat loss in the ACC and equatorial regions and the enhanced heat gain in the subtropical basin. Therefore, the variability in subduction rate may be primarily due to changes in the mixed layer depth in connection with anomalies in surface wind and heat flux. For example, in the ACC region, the anomalous strong westerly winds cool the SST
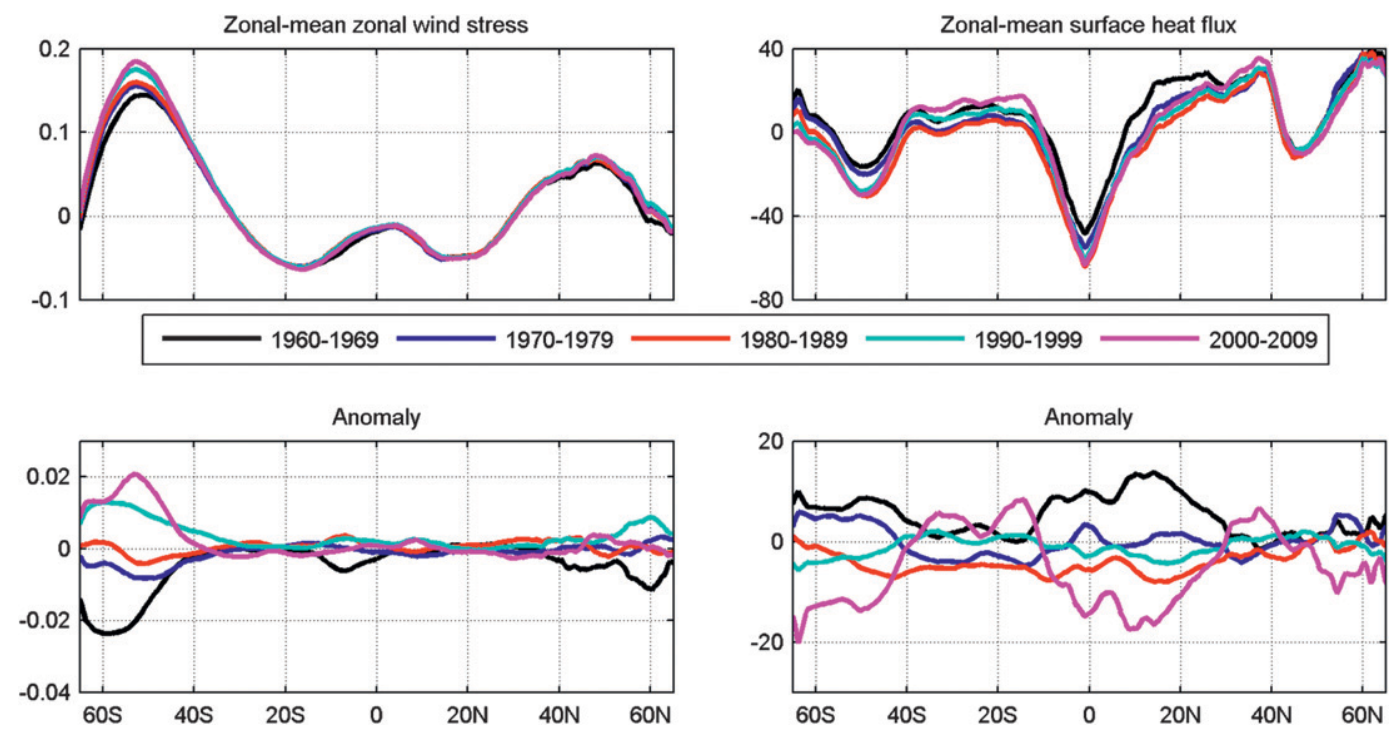

FIG. 11. Meridional distribution (left) of the (top) decadal-mean zonal-mean wind stress ( $\mathrm{Pa}$ ) and (bottom) the anomaly to the long-term mean and (right) of the (top) decadal-mean zonal-mean heat flux ( $\mathrm{W} \mathrm{m}^{-2}$ ) and (bottom) the anomaly to the long-term mean. 

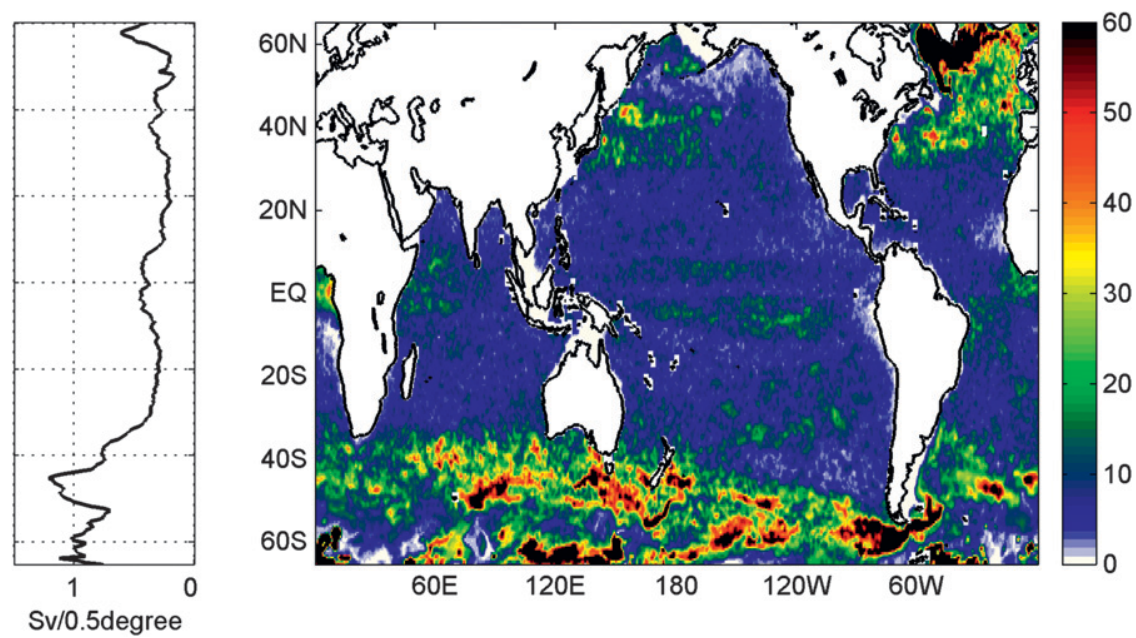

FIG. 12. Standard deviation of the annual subduction rate, in which the temporal trend has been taken out, from 1959 to $2006\left(\mathrm{~m} \mathrm{yr}^{-1}\right)$ and (left) the meridional distribution of the standard deviation variance.

through increasing heat loss to the atmosphere and enhancing mixing in the ocean, thereby resulting in an anomalous deep mixed layer depth, which allows waters to be easily swept into the thermocline by horizontal circulation, suggesting an enhanced subduction rate.

More importantly, the temporal trend of the annual subduction rate during the period from 1959 to 1974 can be attributed to the equatorial band and the Southern Ocean (left panels, Fig. 9). The most interesting phenomenon is that during the period from 1975 to 2006, there is an obvious increasing trend and the amplitude of variability was increased in the Southern Ocean, while the subduction rate in the equatorial band was gradually reduced and the amplitude of variability was also reduced. On the whole, the subduction rate increased $35.3 \%$ (a growth rate of $1.1 \mathrm{~Sv} \mathrm{yr}^{-1}$ ), over the past 50 years in the Southern Ocean, while it decreased $21.6 \%$ (decrement rate of $0.3 \mathrm{~Sv} \mathrm{yr}^{-1}$ ) in the equatorial band. As shown in Fig. 11 , changes in wind stress feature the intensification of westerly winds over the ACC region and the weakening of easterly winds over the equator region; however, in the ACC and equator regions, both heat losses are intensified over the past 50 years. Thus, the opposite trend of the subduction rate in the Southern Ocean and equatorial band may be directly linked to the surface wind. Also, the Southern Ocean becomes a more and more dominant site for water mass formation through subduction and its decadal variability.

The horizontal distribution of interannual variability can be clearly seen from the standard deviation of the subduction rate, in which the temporal trend obtained by a quadratic trend fitting has been taken out considering the regime shift, for the period from 1959 to 2006 (Fig. 12). The meridional distribution of the zonal integral, left panel of Fig. 12, indicates that the Southern Ocean is the most important region with great interannual variability of the subduction rate.

Moreover, Fig. 12 indicates that each basin can contribute to variability of the subduction rate. Accordingly, the time series of the annual subduction rate in each basin are shown in Fig. 13 (top left for North Pacific, top right for South Pacific, middle left for North Atlantic, middle right for South Atlantic, bottom left for North Indian, and bottom right for South Indian). It can be readily seen that there is great interannual variability in each basin; however, the trend in each basin during the periods $1959-74$ and $1975-2006$ is slightly different. For the period from 1959 to 1974, there was an increasing trend in each basin, except for the South Atlantic where the annual subduction rate was slightly decreased. In addition, the rate of increase in the South Pacific and South Indian was quite larger. On the other hand, for the period from 1975 to 2006, the annual subduction rate decreased in the Northern Hemisphere; however, in the Southern Hemisphere there was an obvious increasing trend, except for the South Atlantic. In the same way, variation of the subduction rate in each basin can be ascribed to the lateral induction term (figure omitted), which may be directly linked to the surface wind stress and heat flux.

\section{The obduction rate and its variability}

In addition to the subduction rate, which indicates how much new water is pumped into the permanent pycnocline, 

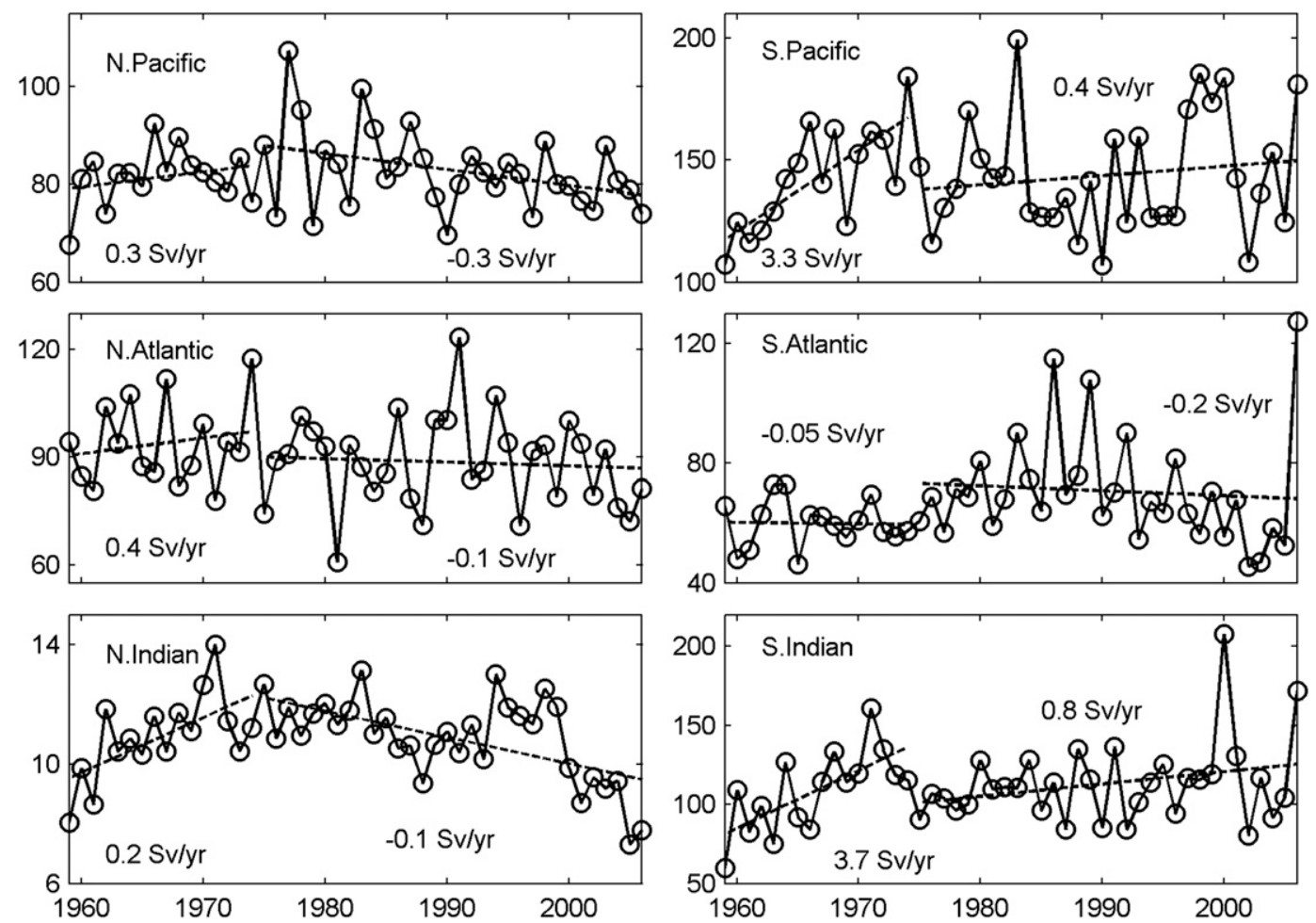

FIG. 13. Times series of the total annual subduction rate from 1959 to 2006 in each basin, as in Fig. 7: numbers inside each panel indicate the growth rate of the total subduction rate in the corresponding period.

we have also calculated the obduction rate, which indicates how fast water in the permanent pycnocline is returned to the mixed layer after cycling through the ocean's interior.

\section{a. The obduction rate}

The annual obduction rate for the global oceans averaged from 1959 to 2006 is shown in Fig. 14. The Southern Ocean and equatorial band are the first and second primary regions of water erosion through obduction, which can be clearly seen from the meridional distribution of the zonally integrated obduction rate (left panel, Fig. 14); the third is the North Atlantic, and the fourth is the North Pacific. The total volume flux over the global oceans averaged from 1959 to 2006 is estimated at $482.1 \mathrm{~Sv}$, with $156.8 \mathrm{~Sv}$ in the Atlantic, 203.2 Sv in the Pacific, and 122.1 Sv in the Indian Ocean. Moreover, the obduction rate integrated over the entire Southern Ocean is 198.9 Sv, Table 2.

Similar to the formation sites of mode water through subduction, the erosion sites of water mass through obduction is shown in Fig. 15, where the number indicates the average potential density in the corresponding outcrop region, which is defined as $\sum_{i} O_{i} \sigma_{i} / \sum_{i} O_{i} ; O_{i}$ and $\sigma_{i}$ are the obduction rate and potential density at each grid. The integration is within each outcrop region as marked in Fig. 15, which is determinded based on the local obduction rate being larger than $100 \mathrm{~m} \mathrm{yr}^{-1}$ in the North Atlantic subpolar gyre and ACC region, $60 \mathrm{~m} \mathrm{yr}^{-1}$ in the equatorial region, and $80 \mathrm{~m} \mathrm{yr}^{-1}$ in other areas. This figure is complementary to Fig. 6 for water mass formation in the World Ocean. These two figures together give a complete picture of water mass formation/erosion in the World Ocean; that is, they show the entrance and exit for water mass cycling in the World Ocean.

One of the most interesting features that Figs. 6 and 15 have in common is the coexistence of subduction and obduction in some parts of the oceans, in particular the Southern Ocean. As discussed by Qiu and Huang (1995), according to the subduction/obduction rate calculation, a local maximum of the mixed layer depth, such as in the ACC region and the recirculation regimes associated with the Gulf Stream and Kuroshio, is essential to "ambiduction," where both subduction and obduction take place but at different times in the seasonal cycle.

The water mass erosion is often related to the upwelling branch of the circulation in the oceans. The strong austral westerlies drive the upwelling in the core of the ACC, which is the strongest large-scale upwelling system in the World Ocean. Accordingly, the strong obduction rate can be found in the ACC region (Figs. 14 and 15).

As discussed in the introduction, calculating water mass erosion through obduction in the open ocean cannot 


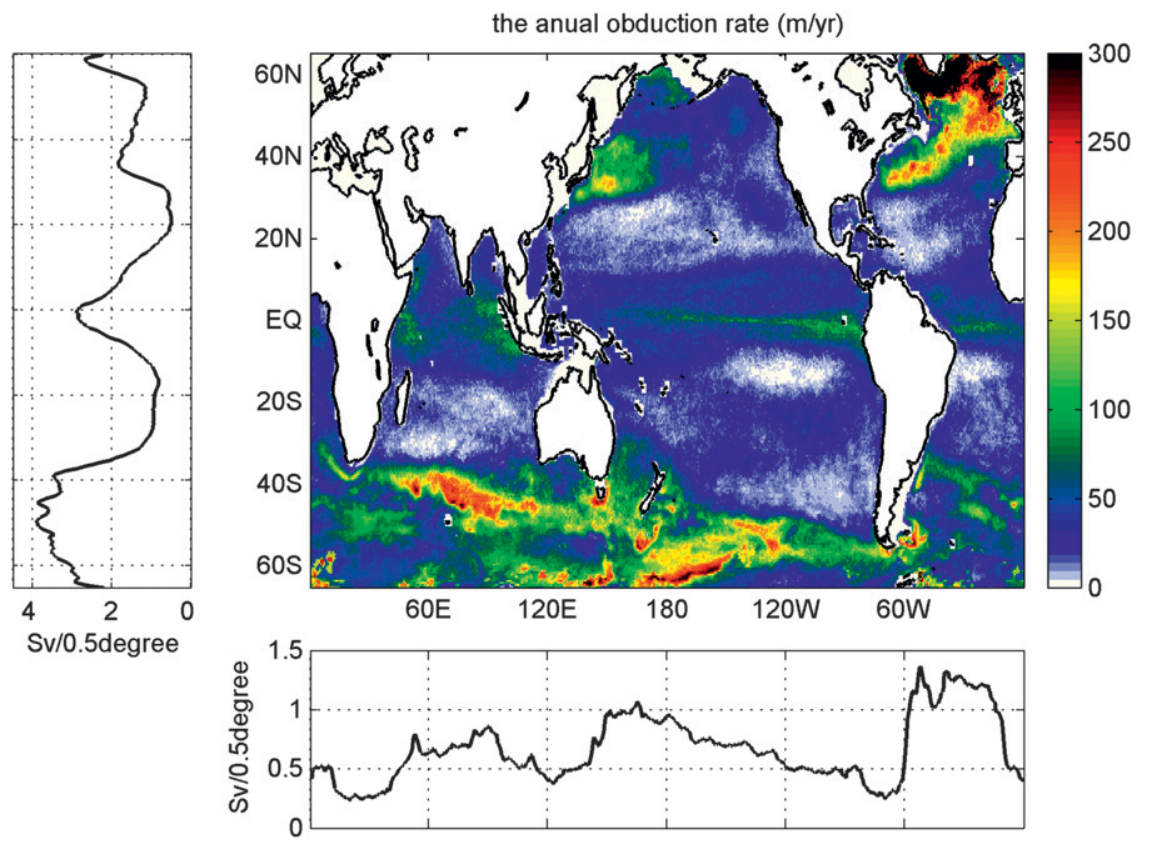

FIG. 14. As in Fig. 4, but for the annual obduction rate.

account for water mass erosion associated with upwelling driven by alongshore wind in some narrow coastal areas. Although Figs. 14 and 15 include some minor contribution near the western coast of the South American continent, they cannot accurately account for the contribution to water mass erosion through strong coastal upwelling along the western coast of South and North America, Africa, and other places. Therefore, Fig. 15 represents water mass erosion through obduction in the open ocean only.

As shown in the bottom panel of Fig. 8, the equatorial band is an important region featuring strong water mass erosion, and the total volume flux in the equatorial band from $10^{\circ} \mathrm{S}$ to $10^{\circ} \mathrm{N}$ is estimated at $87.1 \mathrm{~Sv}$, mainly distributed across the equatorial Pacific and the coastal region, related to the equatorial and strong coastal upwelling along the edges of the basins. For the upper ocean in the equatorial band, there is a net gain of $34.2 \mathrm{~Sv}$ of water transfer (obduction - subduction), which may be balanced by cross-isopycnal mixing and flows across the boundary. This large net water transfer from the permanent pycnocline into the oceanic surface mixed layer may be very important for the local ecosystem, carbon cycle, et cetera.

The distribution of the obduction rate in density coordinates is given in the bottom part of Fig. 5. Similar to calculation of the subduction rate, we first calculate the obduction rate distribution in density coordinates for each year from 1959 to 2006, and then the long-term mean value is obtained by averaging over these years. Furthermore, the difference of subduction and obduction is represented by the black shades. It seems that within $\sigma_{\theta}<22.8$ $\mathrm{kg} \mathrm{m}^{-3}$, mainly distributed in the equatorial region, there is a net water mass erosion (obduction $>$ subduction). However, in the density range $\sigma_{\theta}=22.8-26.6 \mathrm{~kg} \mathrm{~m}^{-3}$, corresponding to the ventilated layer in subtropical gyres, subduction is greater than obduction; then, within $\sigma_{\theta}>26.6 \mathrm{~kg} \mathrm{~m}^{-3}$, there is a large net water mass erosion mainly accumulated in the North Atlantic (3.3 Sv, Table 3) and Southern Ocean (21.5 Sv, Table 3), which can also be seen from the distribution of the difference between subduction and obduction, indicated by black shades, for a given density range for the Southern Ocean (bottom panel, Fig. 7).

In theory, the total amount of water mass formation and erosion going through the base of the mixed layer should be nearly balanced for the World Ocean on the climatological time scale. The total imbalance of $23.7 \mathrm{~Sv}$ (as shown in Table 3 ) diagnosed in our study is less than $5 \%$ of the total subduction rate. Such an error can be due to several reasons: First, the SODA outputs may not represent the water mass cycling climate accurately. Second, as discussed in the introduction, estimating water mass

TABLE 2. As in Table 1, but for the obduction rate.

\begin{tabular}{lcrrr}
\hline \hline & Atlantic & Pacific & Indian & Sum \\
\hline Northern Hemisphere & 93.5 & 75.6 & 12.7 & 181.8 \\
Southern Hemisphere & 63.3 & 127.6 & 109.4 & 300.3 \\
Southern Ocean & 43.1 & 74.4 & 81.4 & 198.9 \\
Sum & 156.8 & 203.2 & 122.1 & 482.1 \\
\hline
\end{tabular}




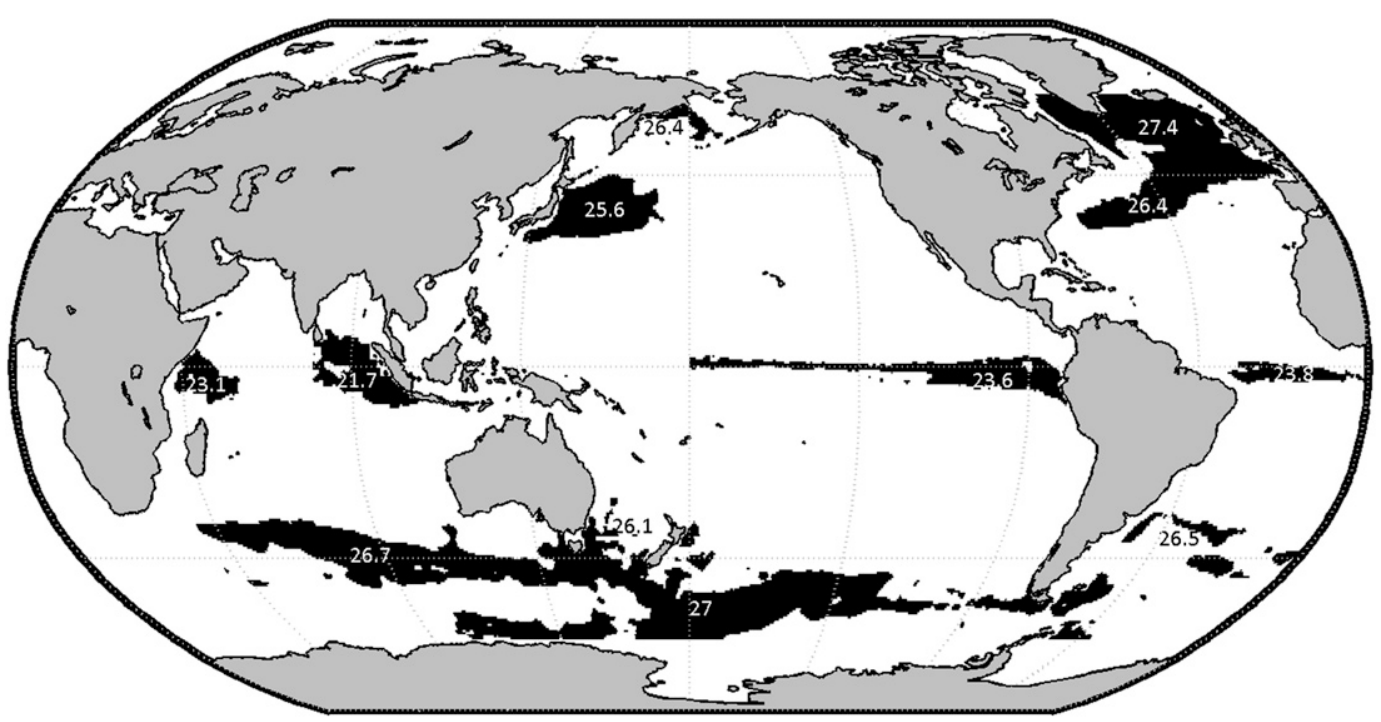

FIG. 15. Sites of water mass erosion through obduction in the World Ocean: the numbers indicate the average potential density within each outcrop region.

formation/erosion through subduction/obduction in the open ocean could not accurately include the contribution associated with water mass formation/erosion in the forms of deep-water/bottom-water formation near coastal zones or semienclosed marginal seas or upwelling/downwelling near narrow coastal zones. Third, an average of a rate over varying times when the volumes themselves should be a quantity that balances may appear to be out of balance because the time interval for averaging could vary in length in some locations. Finally, diffusion, which may contribute to subduction (Musgrave 1990), is not considered. Therefore, a comprehensive water mass formation/ erosion balance on the climatological mean state can be obtained by including these contributions as well.

The distribution of the obduction rate per $0.2 \sigma_{\theta}$ as a function of potential density in each basin is shown in Fig. 7, where the difference of subduction and obduction is represented by black shades. In the North Pacific there are two obduction peaks, one around $\sigma_{\theta}=22.2 \mathrm{~kg} \mathrm{~m}^{-3}$ and the other at $\sigma_{\theta}=25.2 \mathrm{~kg} \mathrm{~m}^{-3}$; however, over the entire North Pacific there is a net water mass formation of $6.8 \mathrm{~Sv}$ (Table 3), mainly accumulated in the density range $\sigma_{\theta}=22.6-25.6 \mathrm{~kg} \mathrm{~m}^{-3}$ in the subtropical gyre. Unlike the North Pacific, there is a net water mass erosion of 3.3 Sv in the North Atlantic (Table 3), accumulated within the density range $\sigma_{\theta}=22-23.8 \mathrm{~kg} \mathrm{~m}^{-3}$ corresponding to the equatorial Atlantic and $\sigma_{\theta}=26.4-27.4 \mathrm{~kg} \mathrm{~m}^{-3}$ corresponding to moving water in the subpolar gyre (Fig. 7). Similarly, in the north Indian Ocean there is a net water mass formation in the subtropical gyre and net erosion in the equatorial gyre (Fig. 7). In the Southern Hemisphere there is a net water mass formation in each basin, as listed in Table 3. However, in the Southern Ocean there is a net water mass erosion through obduction in each basin, which can also be seen in the right panel of Fig. 7 that the obduction is larger than subduction in the corresponding density range for the ACC region.

\section{b. The obduction rate variability}

The time series of the annual obduction rate during the period from 1959 to 2006 is given in the top-right panel of Fig. 9. Similar to the subduction rate, the amplitude of the interannual variability of the global obduction rate before 1975 is small and shows an obvious trend, as illustrated by the dotted line, that increased 31.6\% from 1959 to 1974, with a growth rate of $8.6 \mathrm{~Sv} \mathrm{yr}^{-1}$. Likewise, after 1974 the amplitude of interannual variability is largely increased, while the increasing trend decreases. Over the whole period, the global obduction rate increased $9.8 \%$, with a growth rate of $1 \mathrm{~Sv} \mathrm{yr}^{-1}$, over the past 50 years, slightly larger than the growth rate of the subduction rate $(7.6 \%$,

TABLE 3. Net rate of water mass formation/erosion (Sv) (subduction - obduction) averaged from 1959 to 2006. Note that although the Southern Ocean is listed in the third row, its contributions are part of the Southern Hemisphere.

\begin{tabular}{lcccr}
\hline \hline & Atlantic & Pacific & Indian & Sum \\
\hline Northern Hemisphere & -3.3 & 6.8 & -1.8 & 1.7 \\
Southern Hemisphere & 3.9 & 15.7 & 2.4 & 22.0 \\
Southern Ocean & -6.1 & -4.4 & -11 & -21.5 \\
Sum & & & & \\
& 0.6 & 22.5 & 0.6 & 23.7 \\
& & & &
\end{tabular}



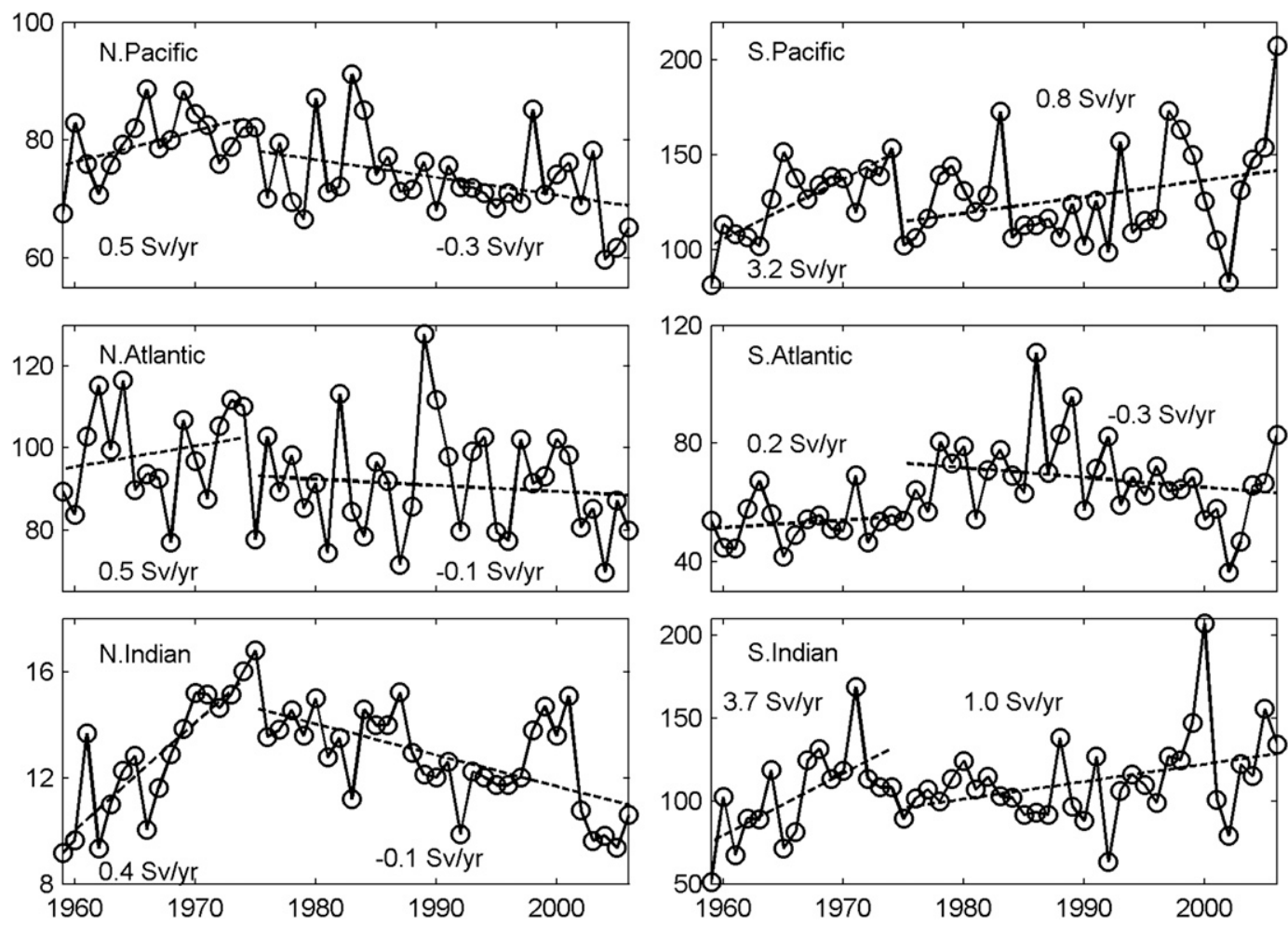

FIG. 16. As in Fig. 13, but for the annual total obduction rate.

$0.8 \mathrm{~Sv} \mathrm{yr}^{-1}$ ). Similar to the case of subduction, the annual variation of the globally integrated obduction rate is primarily attributed to the lateral induction term, as shown in the bottom-left panel of Fig. 10.

Comparison of the new calculations (based on the yearto-year variable mixed layer depth and climatologically mean monthly velocity) and the standard calculations is shown in the bottom-right panel of Fig. 10. From this panel, it is readily seen that the variability in the globally integrated lateral induction is primarily associated with changes in mixed layer depth. Combining the results shown in the bottom panels of Fig. 10, the interannual variability in obduction rate is primarily due to changes in the mixed layer depth, which is in turn related to changes in wind stress and surface heat flux.

As the regions with a strong obduction rate, both the equatorial region and Southern Ocean play key roles in the interannual and decadal variability of the obduction rate. As shown in the right panel of Fig. 9, the trend of the annual obduction rate can be attributed to the equatorial region and the Southern Ocean. Similar to the subduction rate, during the period from 1975 to 2006, there is an obvious increasing trend in the Southern Ocean, while the obduction rate in the equatorial region is gradually reduced. On the whole, the obduction rate increased $38.3 \%$ (with the growth rate of $1.3 \mathrm{~Sv} \mathrm{yr}^{-1}$ ) over the past
50 years in the Southern Ocean, while it decreased 6.3\% (decrement rate of $0.1 \mathrm{~Sv} \mathrm{yr}^{-1}$ ) in the equatorial region. As discussed above, it may be related to intensification of the westerlies over the ACC region and weakening of the easterlies over the equatorial region during the past 50 years, as shown in Fig. 11.

In the same way, the time series of the obduction rate in each basin is shown in Fig. 16. It is readily seen that there is great interannual variability in each basin, and the variation trend in each basin is similar to that of the subduction rate, except in the South Atlantic. In the period from 1959 to 1974 the obduction rates increase in each basin. After 1974 the obduction rates gradually decrease in the Northern Hemisphere and South Atlantic. However, the obduction rates in the South Pacific and south Indian Ocean indicate increasing trends (Fig. 16). Moreover, it can be readily seen, by comparing Figs. 13 and 16, that the increasing (decreasing) rate of the obduction rate is larger than that of subduction, except that the obduction rate is nearly the same in the Northern Hemisphere during the period from 1959 to 1974.

\section{Conclusions}

Subduction/obduction are good indexes for the studies of oceanic general circulation, climate, and the carbon 
cycle; thus, we carried out a systematic calculation to explore ventilation, including subduction and obduction, for the global oceans.

Using SODA outputs from 1958 to 2007, we produced a detailed description of subduction/obduction in the global oceans and their variability. The main results of our study may be summarized as follows.

- The global subduction rate-irreversibe volume flux from the oceanic surface mixed layer to the permanent pycnocline averaged from 1959 to 2006-is estimated at $505.8 \mathrm{~Sv}$, with $157.4 \mathrm{~Sv}$ in the Atlantic, 225.7 Sv in the Pacific, and $122.7 \mathrm{~Sv}$ in the Indian Ocean.

- The global obduction rate- irreversible volume flux from the permanent pycnocline to the mixed layer averaged from 1959 to 2006 -is estimated at $482.1 \mathrm{~Sv}$, with $156.8 \mathrm{~Sv}$ in the Atlantic, 203.2 Sv in the Pacific, and 122.1 Sv in the Indian Ocean.

- The time series of the global subduction/obduction rate suggests strong interannual and decadal variability of water mass formation/erosion. Over the past 50 years, the global subduction rate has increased $7.6 \%$, while the global obduction rate has increased $9.8 \%$, each of which can be largely attributed to changes in the Southern Ocean.

- The equatorial band is an important site of water mass formation/erosion, with the total subduction rate of $52.9 \mathrm{~Sv}$ and total obduction rate of 87.1 Sv. The subduction/obduction rate in the equatorial band show strong variability on interannual and decadal time scales-the subduction rate decreased $21.6 \%$, while the obduction rate decreased $6.3 \%$ over the past 50 years-which may be related to the weakening of the easterlies over the equatorial region.

- The Southern Ocean is the most important region featuring a strong subduction/obduction rate and strong variability on interannual and decadal time scales. In addition, the Southern Ocean is also an important site of ambiduction, where water mass erosion and formation take place at the same location. Thus, the Southern Ocean is a critical site for air-sea interaction and freshening of tracers in the World Ocean. On the whole, the subduction (obduction) rate increases 35.3\% (38.3\%) over the past 50 years. The trend may be related to the intensification of the westerlies over the ACC region.

Our study is only the first step toward quantifying global subduction/obduction rates and their variability; there are several shortcomings. First, since the dataset used in this study has a rather low horizontal resolution $\left(0.5^{\circ} \times 0.5^{\circ}\right)$, the model is incapable of resolving eddies and narrow boundary currents in the ocean. As a result, many critical components of the global water mass cycling cannot be accurately represented in this model; thus, the results obtained from analyzing this dataset can serve as a rather rough first estimate of the global water mass formation/erosion.

Second, the subduction/obduction rate represents the annual mean irreversible volume flux across the base of the annual maximal mixed layer depth only. Water mass formation and transformation taking place within the mixed layer and below the mixed layer are not included in such a kinematic calculation. In particular, bottom-water/ deep-water formation includes at least two steps: formation of the original water mass in the upper ocean and subsequent entrainment in the density current sinking to the deep ocean. Thus, the subduction/obduction rate is one aspect of the water mass balance in the World Ocean.

Third, data processing, such as the usage of model vertical velocities and the preprocessing performed to derive the SODA datasets, may induce large errors.

In addition, according to Trossman et al. (2009), the horizontal and temporal structure of the mixed layer depth is the primary factor that controls ventilation. In fact, the so-called base of the mixed layer is an idealization of the complicated structure in the upper ocean, and different criteria for estimating the mixed layer depth can induce a large difference in the subduction rate. In particular, the usage of a density-based criterion for estimating the mixed layer depth may also induce errors. It is difficult to quantify the error associated with the processing of data generated by a data-assimilated model such as SODA. Estimating the errors associated with our results are beyond the scope of this manuscript. Because the errors in our estimated subduction and obduction rates could be on the order of $10 \%$, it is possible that the subduction and obduction rate trends found in this study may be insignificant. However, as discussed above, the variability in the mixed layer depth is the primarily cause for variability in the subduction/obduction rate. Thus, how much of the trend diagnosed from the SODA assimilation product represents the real physical trend in the oceans remains unknown and is left for further study.

Acknowledgments. We thank three reviewers for their insightful suggestions and comments. This work was supported by the Key State Basic Research Program of China under Grant 2012CB417401, the National Natural Science Foundation of China (Grants 40906007, 40890152), and the Open Foundation of Physical Oceanography Laboratory, OUC, under Grant 200902.

\section{REFERENCES}

Banks, H. T., R. A. Wood, J. M. Gregory, T. C. Johns, and G. S. Jones, 2000: Are observed decadal changes in the intermediate 
water masses a signal of anthropogenic climate change? Geophys. Res. Lett., 27, 2961-2964.

Bindoff, N. L., and J. A. Church, 1992: Warming of the water column in the southwest Pacific Ocean. Nature, 357, 59-62.

— , and T. J. McDougall, 2000: Decadal changes along an Indian Ocean section at $32^{\circ} \mathrm{S}$ and their interpretation. J. Phys. Oceanogr., 30, 1207-1222.

Boyer, T. P., and Coauthors, 2006: World Ocean Database 2005. NOAA Atlas NESDIS 60, 182 pp.

Brambilla, E., and L. D. Talley, 2008: Subpolar mode water in the northeastern Atlantic: 1. Averaged properties and mean circulation. J. Geophys. Res., 113, C04025, doi:10.1029/ 2006JC004062.

,-- , and P. E. Robbins, 2008: Subpolar mode water in the northeastern Atlantic: 2. Origin and transformation. J. Geophys. Res., 113, C04026, doi:10.1029/2006JC004063.

Brandt, P., A. Funk, L. Czeschel, C. Eden, and C. W. Böing, 2007: Ventilation and transformation of Labrador Sea Water and its rapid export in the deep Labrador Current. J. Phys. Oceanogr., 37, 946-961.

Bryden, H. L., and H. M. Stommel, 1982: Origin of the Mediterranean outflow. J. Mar. Res., 40, 55-71.

Carton, J. A., and B. S. Giese, 2008: A reanalysis of ocean climate using SODA. Mon. Wea. Rev., 136, 2999-3017.

_ G. Ghepurin, X. Gao, and B. S. Giese, 2000: A Simple Ocean Data Assimilation analysis of the global upper ocean 1950-95. Part I: Methodology. J. Phys. Oceanogr., 30, 294-309.

Garrett, C., and A. Tandon, 1997: The effects on water mass formation of surface mixed layer time-dependence and entrainment fluxes. Deep-Sea Res. I, 44, 1991-2006.

_, K. Speer, and E. Tragou, 1995: The relationship between water mass formation and the surface buoyancy flux, with application to Phillips' Red Sea model. J. Phys. Oceanogr., 25, 1696-1705.

Halpern, D., R. A. Knox, D. S. Luther, and S. G. H. Philander, 1989: Estimates of equatorial upwelling between $140^{\circ}$ and $110^{\circ} \mathrm{W}$ during 1984. J. Geophys. Res., 94, 8018-8020.

Hanawa, K., and L. D. Talley, 2001: Mode waters. Ocean Circulation and Climate, G. Siedler, J. Church, and J. Gould, Eds., International Geophysics Series, Vol. 77, Academy Press, 373-386.

Hautala, S. L., and D. H. Roemmich, 1998: Subtropical mode water in the northeast Pacific basin. J. Geophys. Res., 103, 13 055-13066.

Hellerman, S., and M. Rosenstein, 1983: Normal monthly wind stress over the World Ocean with error estimates. J. Phys. Oceanogr., 13, 1093-1104.

Huang, R. X., 1988a: Ideal-fluid thermocline with weakly convective adjustment in a subpolar basin. J. Phys. Oceanogr., 18, 642-651.

— 1988b: On boundary value problems of the ideal-fluid thermocline. J. Phys. Oceanogr., 18, 619-641.

_ 1990: On the three-dimensional structure of the wind-driven circulation in the North Atlantic. Dyn. Atmos. Oceans, 15, 117-159.

— and B. Qiu, 1998: The structure of the wind-driven circulation in the subtropical South Pacific Ocean. J. Phys. Oceanogr., 28, $1173-1186$

Iselin, C. O. D., 1939: The influence of vertical and lateral turbulence on the characteristics of the waters at mid-depths. Trans. Amer. Geophys. Union, 20, 414-417.

Johnson, G. C., and A. H. Orsi, 1997: Southwest Pacific Ocean water-mass changes between 1968/69 and 1990/91. J. Climate, 10, 306-316.
- M. J. McPhaden, and E. Firing, 2001: Equatorial Pacific Ocean horizontal velocity, divergence, and upwelling. J. Phys. Oceanogr., 31, 839-849.

Karstensen, J., and D. Quadfasel, 2002: Formation of Southern Hemisphere thermocline waters: Water mass conversion and subduction. J. Phys. Oceanogr., 32, 3020-3038.

LeBel, D. A., and Coauthors, 2008: The formation rate of North Atlantic Deep Water and Eighteen Degree Water calculated from CFC-11 inventories observed during WOCE. Deep-Sea Res. I, 55, 891-910.

Lumpkin, R., and K. Speer, 2003: Large-scale vertical and horizontal circulation in the North Atlantic Ocean. J. Phys. Oceanogr., 33, 1902-1920.

Luyten, J. R., J. Pedlosky, and H. M. Stommel, 1983: The ventilated thermocline. J. Phys. Oceanogr., 13, 292-309.

Mantua, N. J., S. R. Hare, Y. Zhang, J. Wallace, and R. C. Francis, 1997: A Pacific interdecadal climate oscillation with impacts on salmon production. Bull. Amer. Meteor. Soc., 78, 1069-1079.

Marshall, D., 1997: Subduction of water masses into the eddying ocean. J. Mar. Res., 55, 201-222.

Marshall, J. C., A. J. G. Nurser, and R. G. Williams, 1993: Inferring the subduction rate and period over the North Atlantic. J. Phys. Oceanogr., 23, 1315-1329.

_ D. Jamous, and J. Nilsson, 1999: Reconciling thermodynamic and dynamic methods of computation of water-mass transformation rates. Deep-Sea Res. I, 46, 545-572.

Masuzawa, J., 1969: Subtropical mode water. Deep-Sea Res., 16, $463-472$.

McCartney, M. S., 1982: The subtropical recirculation of mode waters. J. Mar. Res., 40, 427-464.

_ and L. D. Talley, 1982: The subpolar mode water of the North Atlantic. J. Phys. Oceanogr., 12, 1169-1188.

Musgrave, D. L., 1990: Numerical studies of tritium and helium-3 in the thermocline. J. Phys. Oceanogr., 20, 344-373.

Nakamura, H., 1996: A pycnostad on the bottom of the ventilated portion in the central subtropical North Pacific: Its distribution and formation. J. Oceanogr., 52, 171-188.

_, G. Lin, and T. Yamagata, 1997: Decadal climate variability in the North Pacific during recent decades. Bull. Amer. Meteor. Soc., 78, 2215-2225.

Nurser, A. J. G., R. Marsh, and R. G. Williams, 1999: Diagnosing water mass formation from air-sea fluxes and surface mixing. J. Phys. Oceanogr., 29, 1468-1487.

Orsi, A. H., G. C. Jonhnson, and J. L. Bullister, 1999: Circulation, mixing and production of Antarctic Bottom Water. Prog. Oceanogr., 43, 55-109.

Provost, C., C. Escoffier, K. Maamaatuaiahutapu, A. Kartavtseff, and V. Garçon, 1999: Subtropical mode waters in the South Atlantic Ocean. J. Geophys. Res., 104, 21 033-21 049.

Qiu, B., and R. X. Huang, 1995: Ventilation of the North Atlantic and North Pacific: Subduction versus obduction. J. Phys. Oceanogr., 25, 2374-2390.

Qu, T., and J. Chen, 2009: A North Pacific decadal variability in subduction rate. Geophys. Res. Lett., 36, L22602, doi:10.1029/ 2009GL040914.

— S.-P. Xie, H. Mitsudera, and A. Ishida, 2002: Subduction of the North Pacific mode waters in a global high-resolution GCM. J. Phys. Oceanogr., 32, 746-763.

— S. Gao, I. Fukumori, R. A. Fine, and E. J. Lindstrom, 2008: Subduction of South Pacific waters. Geophys. Res. Lett., 35 , L02610, doi:10.1029/2007GL032605.

Roemmich, D., and B. Cornuelle, 1992: The subtropical mode waters of the South Pacific Ocean. J. Phys. Oceanogr., 22, 1178-1187. 
Sarmiento, J. L., and J. R. Toggweiler, 1984: A new model for the role of the oceans in determining atmospheric $\mathrm{PCO}_{2}$. Nature, 308, 621-624.

Siedler, G., A. Kuhl, and W. Zenk, 1987: The Madeira Mode Water. J. Phys. Oceanogr., 17, 1561-1570.

Speer, K. G., 1997: A note on average cross-isopycnal mixing in the North Atlantic Ocean. Deep-Sea Res., 44, 1981-1990.

- , and E. Tziperman, 1992: Rates of water mass formation in the North Atlantic Ocean. J. Phys. Oceanogr., 22, 93-104.

— - H. J. Isemer, and A. Biastoch, 1995: Water mass formation from revised COADS data. J. Phys. Oceanogr., 25, 2444-2457.

Stommel, H. M., 1979: Determination of water mass properties of water pumped down from the Ekman layer to the geostrophic flow below. Proc. Natl. Acad. Sci. USA, 76, 30513055.

Suga, T., K. Hanawa, and Y. Toba, 1989: Subtropical mode water in the $137^{\circ}$ E section. J. Phys. Oceanogr., 19, 1605-1618.

_- Y. Takei, and K. Hanawa, 1997: Thermostad distribution in the North Pacific subtropical gyre: The central mode water and the subtropical mode water. J. Phys. Oceanogr., 27, 140-152.

Toole, J. M., and B. A. Warren, 1993: A hydrographic section across the subtropical south Indian Ocean. Deep-Sea Res., 40, 1973-2019.

Trossman, D. S., L. Thompson, K. A. Kelly, and Y.-O. Kwon, 2009: Estimates of North Atlantic ventilation of mode water formation for winters 2002-06. J. Phys. Oceanogr., 39, 26002617.
Tsuchiya, M., and L. D. Talley, 1996: Water-property distributions along an eastern Pacific hydrographic section at $135^{\circ} \mathrm{W}$. J. Mar. Res., 54, 541-564.

$\longrightarrow,-$, and M. C. McCartney, 1994: Water-mass distributions in the western South Atlantic; a section from South Georgia Island (54S) northward across the equator. J. Mar. Res., 52, 55-81.

Walin, G., 1982: On the relation between sea-surface heat flow and thermal circulation in the ocean. Tellus, 34, 187-195.

Weisberg, R. H., and L. Qiao, 2000: Equatorial upwelling in the central Pacific estimated from moored velocity profilers. J. Phys. Oceanogr., 30, 105-124.

Williams, R. G., 1991: The role of the mixed layer in setting the potential vorticity of the main thermocline. J. Phys. Oceanogr., 21, 1802-1814.

_- M. A. Spall, and J. C. Marshall, 1995: Does Stommel's mixed layer "demon" work? J. Phys. Oceanogr., 25, 3089-3102.

Wong, A. P. S., N. L. Bindoff, and J. A. Church, 1999: Large scale freshening of intermediate waters in the Pacific and Indian Oceans. Nature, 400, 440-443.

Woods, J. D., 1985: The physics of thermocline ventilation. Coupled Ocean-Atmosphere Models, J. C. J. Nihoul, Ed., Elsevier Oceanography Series, Elsevier Science Publishers, 543-590.

_ _ and W. Barkmann, 1986: A Lagrangian mixed layer model of Atlantic $18^{\circ} \mathrm{C}$ water formation. Nature, 319, 574-576.

Worthington, L. V., 1959: The $18^{\circ}$ water in the Sargasso Sea. DeepSea Res., 5, 297-305. 